\title{
The Tropospheric Pathway of the ENSO-North Atlantic Teleconnection
}

\section{Journal Article}

Author(s):

Jiménez Esteve, Bernat (D); Domeisen, Daniela (i)

Publication date:

2018-06-01

Permanent link:

https://doi.org/10.3929/ethz-b-000251043

Rights / license:

In Copyright - Non-Commercial Use Permitted

Originally published in:

Journal of Climate 31(11), https://doi.org/10.1175/jcli-d-17-0716.1

Funding acknowledgement:

170523 - Improving the Prediction of Sub-seasonal to Seasonal Weather and Climate - From Theory to Application (SNF) 


\title{
The Tropospheric Pathway of the ENSO-North Atlantic Teleconnection
}

\author{
BERnAt JiMÉNEZ-ESTEVE AND DANIELA I. V. DOMEISEN \\ Institute for Atmospheric and Climate Science, ETH Zurich, Zurich, Switzerland
}

(Manuscript received 20 October 2017, in final form 1 February 2018)

\begin{abstract}
El Niño-Southern Oscillation (ENSO) exerts an influence on the North Atlantic-European (NAE) region. However, this teleconnection is nonlinear and nonstationary owing to the superposition and interaction of a multitude of influences on this region. The stratosphere is one of the major players in terms of the influence of the ENSO signal on this sector. Nevertheless, there are tropospheric dynamical links between the North Pacific and the North Atlantic that are clearly influenced by ENSO. This tropospheric pathway of ENSO to the NAE has received less attention. In view of this, the present study revisits the tropospheric pathway of ENSO to the North Atlantic using ECMWF reanalysis products. Anomalous propagation of transient and quasi-stationary waves across North America is analyzed with respect to their sensitivity to ENSO. Transient (quasi-stationary zonal waves 1-3) wave activity flux (WAF) from the Pacific to the Atlantic increases during El Niño (La Niña) conditions leading to a negative (positive) phase of the North Atlantic Oscillation (NAO). This response is observed from January to March for El Niño and only visible during February for La Niña events. However, the stratosphere strongly modulates this response. For El Niño (La Niña) conditions a weaker (stronger) stratospheric vortex tends to reinforce the negative (positive) NAO with the stratosphere and troposphere working in tandem, contributing to a stronger and more persistent tropospheric circulation response. These findings may have consequences for the prediction of the NAO during times with an inactive stratosphere.
\end{abstract}

\section{Introduction}

El Niño-Southern Oscillation (ENSO) is the dominant mode of interannual climate variability in the tropics. Atmosphere-ocean feedbacks are responsible for changes in surface winds, pressure, and sea surface temperature during the changes between the warm phase [El Niño (EN)] and the cold phase [La Niña (LN)], which occur with an irregular period of 2-7 years. Tropical atmospheric circulation anomalies can influence the extratropics, generally referred to as teleconnection patterns (Liu and Alexander 2007). The ENSO signal is suggested to reach the North Atlantic and Eurasia through a variety of mechanisms, including pathways through the tropical Atlantic (Sung et al. 2013) and the stratosphere via the North Pacific (RodríguezFonseca et al. 2016; Brönnimann 2007, and references therein). This variety of influences acting on different time scales adds nonlinearity to the system (LópezParages et al. 2016). From the tropical Pacific the ENSO

Corresponding author: Bernat Jiménez-Esteve, bernat.jimenez@ env.ethz.ch signal propagates poleward via Rossby wave trains in the upper troposphere (Hoskins and Karoly 1981) in early winter. In the North Pacific, this contributes to a deepening (weakening) of the winter Aleutian low pressure system (AL) for El Niño (La Niña), and hence to a strengthening (weakening) of the Pacific-North American (PNA) pattern (Horel and Wallace 1981). This part of the remote influence depends on factors like the timing, the strength, and the longitudinal distribution of the tropical Pacific SST forcing (Frauen et al. 2014; Feng et al. 2017). From the North Pacific anomalies can reach the North Atlantic where El Niño (La Niña) tends to be associated with a negative (positive) North Atlantic Oscillation (NAO) phase during late winter. Nonlinearities also exist with regard to the strength of the forcing; for example, Toniazzo and Scaife (2006) find that strong El Niño events tend to have the opposite response in the Atlantic sector (i.e., a positive NAO).

One key factor controlling the Northern Hemisphere ENSO response is the winter polar stratosphere. It is highly variable and is characterized by extreme events, so-called sudden stratospheric warming (SSW) events. 
ENSO is suggested to substantially alter the mean state of the stratospheric polar vortex, as well as the SSW frequency (Manzini 2009). In reanalysis, Butler and Polvani (2011) find an increase of $50 \%$ for the SSW frequency during ENSO years, both during El Niño and La Niña. However, a recent study by Polvani et al. (2017) only finds an increase of about 30\% during El Niño years and no significant change for La Niña, which suggests that the majority of the SSWs occur independently of the ENSO forcing. Both observational and modeling studies agree that weak polar vortex conditions prevail during El Niño winters. Garfinkel et al. (2010) find that the two regional anomalies that most effectively modulate the vortex are the Aleutian low and the Siberian high. The former results in an increase of wave 1 and the latter in an increase of wave 2 (Barriopedro and Calvo 2014), which tend to propagate upward and can weaken the vortex. Therefore, the dominant pathway through which ENSO modulates the vortex is via the Aleutian low and wave- 1 amplification during El Niño conditions. The zonal wind and temperature anomalies in the stratosphere propagate downward in late winter (Plumb and Semeniuk 2003) and often project on the NAO pattern, leading to a meridional shift in the storm track (Ineson and Scaife 2009; Kidston et al. 2015). Furthermore, it has been reported that El Niño leads to an anomalously negative NAO only in winters when SSW events occur (e.g., Butler et al. 2014; Richter et al. 2015), which Domeisen et al. (2015) and Butler et al. (2016) find to be an important source of seasonal predictability over the North Atlantic-European (NAE) region.

However, the stratospheric pathway is not the only way through which ENSO can influence the NAE sector. The North Pacific can in addition have an impact downstream on the North Atlantic via the troposphere. Energy and momentum can be carried by quasistationary Rossby wave trains or transient eddies propagating along the subtropical jet and establishing a dynamical link between the main modes of variability in the North Pacific and Atlantic basins (i.e., the PNA and the NAO). There have been different suggestions of mechanisms for this tropospheric pathway: $\mathrm{Li}$ and Lau (2012b) suggest that the downstream propagation of transient eddies from the North Pacific basin to the North Atlantic is increased during El Niño conditions, leading to a negative geopotential anomaly in the southern lobe of the NAO and projecting onto a negative NAO pattern. Another possible mechanism is suggested by Pinto et al. (2011), proposing that this link could be driven by enhanced baroclinicity in the Newfoundland region during negative PNA events, which tend to happen more often during La Niña winters. At the same time Drouard et al. $(2013,2015)$ emphasize that not only the increase in the downstream propagation of synoptic eddies is important, but also the meridional tilt of the propagation, which preconditions the type of Rossby wave breaking (i.e., anticyclonic or cyclonic; Hoskins et al. 1983; Drouard et al. 2015). While cyclonic wave breaking leads to negative geopotential anomalies, anticyclonic leads to positive anomalies in the NAE. Using a simplified model, Drouard et al. (2013) find that a ridge in the North Pacific region deflects the eddies, which enter the Atlantic with a southwest-northeast tilt, and favors anticyclonic wave breaking, triggering the positive NAO during La Niña. In contrast, during El Niño, synoptic eddies associated with the southward-shifted Pacific storm track exhibit more zonal propagation and increase the likelihood of a negative NAO in the Atlantic. Transient eddies propagating across North America and downstream to the North Atlantic will be further investigated in the present study.

Quasi-stationary Rossby wave trains also propagate from the Pacific to the Atlantic. Several studies focus on the Aleutian low-Icelandic low (AL-IL) seesaw (Honda and Nakamura 2001; Nakamura and Honda 2002; Honda et al. 2005a,b; Liu and Alexander 2007; Orsolini et al. 2008; Sun and Tan 2013). Honda et al. (2001) use a limited reanalysis period (1973-94) showing that a negative correlation between the two quasistationary pressure systems is stronger in late winter, with the Pacific leading the Atlantic. They suggest a stationary Rossby wave train emanating from the PNA as the main mechanism for this teleconnection. In other words, wave activity propagates from the Pacific across North America in the form of quasi-stationary waves, generating stationary anomalies in the Atlantic. These anomalies are maintained by transient eddies propagating along the Atlantic storm track. Castanheira and Graf (2003) and Sun and Tan (2013) also show that the AL-IL seesaw formation mechanism is strongly influenced by the stratosphere; that is, a stronger vortex is more likely to reflect long stationary waves into the troposphere. The majority of these studies highlight that this connection experiences a significant modulation in strength, suggesting an important role of multidecadal variability and a nonstationary behavior of this teleconnection (Pinto et al. 2011; Honda et al. 2005b). The role of quasi-stationary waves in the ENSO teleconnection to the North Atlantic will be further discussed in this work.

While most of the above literature focuses on one particular phenomenon, it is still unclear which mechanisms are the most important for the ENSO-NAE teleconnection. In this study we therefore address the 
TABLE 1. Number of events considered for the composites. We use a threshold of 0.6 standard deviations for the NAM index to define polar vortex late winter mean states (January-March). Two thresholds ( 1 and 0.5 standard deviations) are chosen for the Niño-3.4 index in order to define ENSO phase (November-March).

\begin{tabular}{lcccr}
\hline \hline Period: 1958-2016 (58 years) & No. of events & Strong vortex (18) & Weak vortex (17) & Neutral vortex (23) \\
\hline El Niño (1 std dev) & 11 & 0 & 3 & 8 \\
La Niña (1 std dev) & 11 & 6 & 4 & 1 \\
Neutral ENSO (1 std dev) & 36 & 12 & 5 & 14 \\
El Niño (0.5 std dev) & 21 & 4 & 8 & 12 \\
La Niña (0.5 std dev) & 24 & 10 & 4 & 6 \\
Neutral ENSO (0.5 std dev) & 13 & 4 & 5 \\
\hline
\end{tabular}

following questions: What is the circulation response in the Atlantic forced by the anomalous propagation of quasi-stationary versus transient eddies originating in the Pacific? How is this propagation modulated by ENSO? How does the stratosphere influence this connection? Thus the goal of the present study is to examine the relative role of the tropospheric processes of the ENSO teleconnection to the NAE sector, as well as to contrast its relative importance with the stratospheric pathway. Additional influences on ENSO teleconnections like the sensitivity to the region of maximum SST anomalies in the tropical Pacific (the ENSO flavor) (Deser et al. 2017; Calvo et al. 2017; Iza and Calvo 2015; Garfinkel et al. 2013) or the quasi-biennial oscillation (QBO) (Hansen et al. 2016; Garfinkel and Hartmann 2010; Calvo et al. 2009) will not be considered in this study owing to the small sample size available in reanalysis data.

The paper is organized as follows: A description of the reanalysis data and methods is provided in section 2. In section 3, we review the ENSO winter Northern Hemisphere teleconnection, focusing on the seasonal evolution of the surface circulation response. Section 4 deals with the tropospheric circulation response due to the anomalous propagation of quasi-stationary waves and transient eddies as well as its dependence on ENSO. In section 5 , the winter seasonal evolution of tropospheric processes of the teleconnection is presented independently of the stratospheric forcing, while section 6 analyzes the stratospheric influence on the previously described processes. We close in section 7 with a summary and discussion of the main results.

\section{Data and methods}

\section{a. Datasets and index definitions}

We use daily 3D atmospheric fields from the European Centre for Medium-Range Weather Forecasts ERA-40 (Uppala et al. 2005) (January 1958-December 1978) and ERA-Interim (Dee et al. 2011) (January 1979-December 2016), resulting in a total of 59 years
(1958-2016). For consistency the 23 vertical levels in ERA-40 are interpolated to the 37 ERA-Interim pressure levels. Note that the levels are almost identical above $500 \mathrm{hPa}$ in both datasets, and the results presented here are not sensitive to this interpolation. The same analysis was repeated using JRA-55 (Kobayashi et al. 2015) with no significant changes to the results. The anomalies of atmospheric variables are always computed with respect to the climatology of the full period.

To classify ENSO events the Extended Reconstructed Sea Surface Temperature (ERSST) version 4 dataset (Huang et al. 2015) is used. El Niño and La Niña events are defined based on the standardized detrended November-March (NDJFM) mean sea surface temperature (SST) anomalies in the Niño-3.4 region $\left(5^{\circ} \mathrm{N}-\right.$ $\left.55^{\circ} \mathrm{S}, 170^{\circ}-120^{\circ} \mathrm{W}\right)$. Generally, except when explicitly stated, we consider an EN (LN) event when the anomalies of the Niño-3.4 index are greater (smaller) than one standard deviation. This yields $11 \mathrm{EN}$ and $11 \mathrm{LN}$ events (see Table 1). The analysis has been repeated choosing a 0.5 standard deviation threshold and comparable results were obtained, although the signal gets weaker, in particular for LN events (Iza et al. 2016).

The mean state of the polar vortex is measured using the northern annular mode (NAM) index, defined as the principal component of the dominant EOF at each pressure level of the latitude-longitude fields of geopotential height anomalies north of $20^{\circ} \mathrm{N}$. Using zonally averaged geopotential yields comparable results. The reader is referred to Baldwin and Thompson (2009) for a comprehensive discussion on NAM indices. Then the index is averaged over January-March (JFM) and from 10 to $100 \mathrm{hPa}$. The same weight is used for all levels, but a sensitivity test reveals that the index is not sensitive to the pressure weighting of the levels. The index is linearly detrended and standardized. This definition is dominated by the variability of the lower stratosphere, which is more strongly coupled to the tropospheric response. We use 0.6 standard deviations as a threshold to classify the mean stratosphere polar night vortex, which yields 18 strong, 17 weak, and 23 neutral vortex events (see Table 1). When combining stratosphere and ENSO 
composites, the ENSO threshold is reduced from 1 to 0.5 standard deviations in order to increase the sample size. Note that the conclusions hold when using a threshold of one standard deviation when more than one event is available.

\section{b. Dynamical diagnostics}

We apply a series of dynamical diagnostics. As a first step, the wave activity flux (WAF) for quasi-stationary and transient waves is introduced. In particular, we apply two different formulations of the WAF: the first one is valid for quasi-stationary planetary waves (Plumb 1985, hereinafter PB85), whereas the second one is suitable for transient waves (Plumb 1986, hereinafter PB86). The two formulations differ qualitatively: the stationary WAF is based on zonal mean deviations, whereas the transient WAF uses time perturbations or high-frequency filtered atmospheric anomalies. Furthermore, we are particularly interested in assessing how the propagation of such waves can contribute to the low-frequency background state, which in this study we define as the 30-day low-passfiltered anomalies of the main atmospheric variables. We also apply the transient eddy feedback diagnostic (Lau and Holopainen 1984), which enables us to understand and quantify how much the background slow-varying geopotential field changes due to transient eddy vorticity advection. Last, we focus on the influence of baroclinicity variations. In the following subsections these diagnostics are briefly introduced.

\section{1) WAF FOR STATIONARY AND TRANSIENT EDDIES}

PB85 developed a generalization of the widely used Eliassen-Palm (EP) flux (Edmon et al. 1980). This flux is a useful diagnostic of three-dimensional Rossby wave propagation for stationary waves. In the limit of almostplane waves this flux is a phase-independent quantity, which is parallel to the group velocity of the waves. In the presence of nonconservative effects, the divergence (convergence) of this flux is related to sources (sinks) of wave activity, and hence to a deceleration (acceleration) of the mean flow. When zonally averaged this flux reduces to the conventional EP flux in its quasigeostrophic approximation. See appendix A for the mathematical formulation of this flux.

PB86 developed an equivalent theory based on time deviations of the mean flow. This formulation allows for the tracking of transient wave propagation through the mean flow. One of the interesting properties is that it is independent of phase speed, which makes it easier to numerically compute compared to other formulations such as Takaya and Nakamura $(1997,2001)$ where phase speed needs to be inferred a priori. In contrast to the stationary formulation, the PB86 flux has not been widely used in the literature. However, this diagnostic is a useful tool to diagnose the role of transient waves in atmosphere. See appendix B for the complete mathematical formulation based on Nakamura et al. (2010, 2011).

Previous to the application of the above WAF formulations atmospheric variables are time-filtered using daily resolution. We refer to quasi-stationary (QS) waves when atmospheric variables are low-pass filtered using a Lanzcos filter with a cutoff period of 10 days. Equivalently we refer to transient eddies when atmospheric variables are bandpass filtered with a period between 2 and 8 days.

\section{2) TRANSIENT EDDY FEEDBACK IN TERMS OF GEOPOTENTIAL TENDENCY}

The barotropic feedback of the transient eddies on the background low-frequency mean flow is diagnosed using the quasigeostrophic geopotential tendency equation (see appendix $\mathrm{C}$ for a complete mathematical description). This diagnostic allows us to quantify the forcing of the mean flow by the transient eddies and therefore to analyze the contribution of transient eddies to the geopotential height anomalies during different ENSO phases. In the approximation we use here only contributions of the vorticity advection are considered, the dominant term in the upper troposphere. This approximation is the main reason we restrict our analysis to the $250-\mathrm{hPa}$ isobaric surface. This diagnostic has been used in previous studies to study the effect of downstream propagation of transient eddies on the geopotential (e.g., Li and Lau 2012b,a).

\section{3) EADY GROWTH RATE}

The maximum Eady growth rate (EGR) is calculated to study changes in baroclinicity and to analyze its feedback on the circulation changes. It is given by

$$
\sigma_{E}=0.3098 \frac{|f|\left|\frac{\partial u}{\partial z}\right|}{N}
$$

(Vallis 2013), where $N$ is the Brunt-Väisälä frequency $N^{2}=(g / \theta)(\partial \theta / \partial z), g$ is the acceleration due to gravity, $\theta$ is the potential temperature, and $f$ is the Coriolis parameter.

\section{The Northern Hemispheric circulation response to ENSO}

In this section we briefly revisit the ENSO influence on the Northern Hemispheric circulation from reanalysis data. 


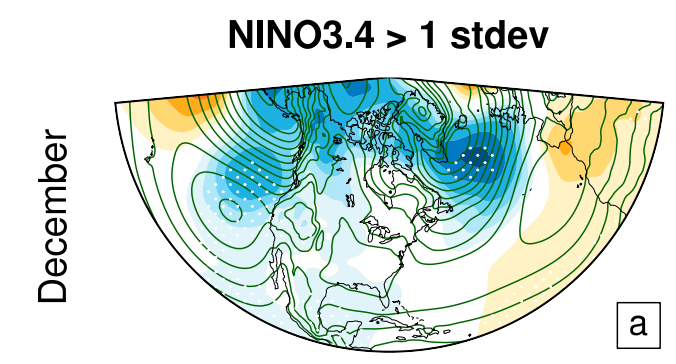

NINO3.4 $<-1$ stdev
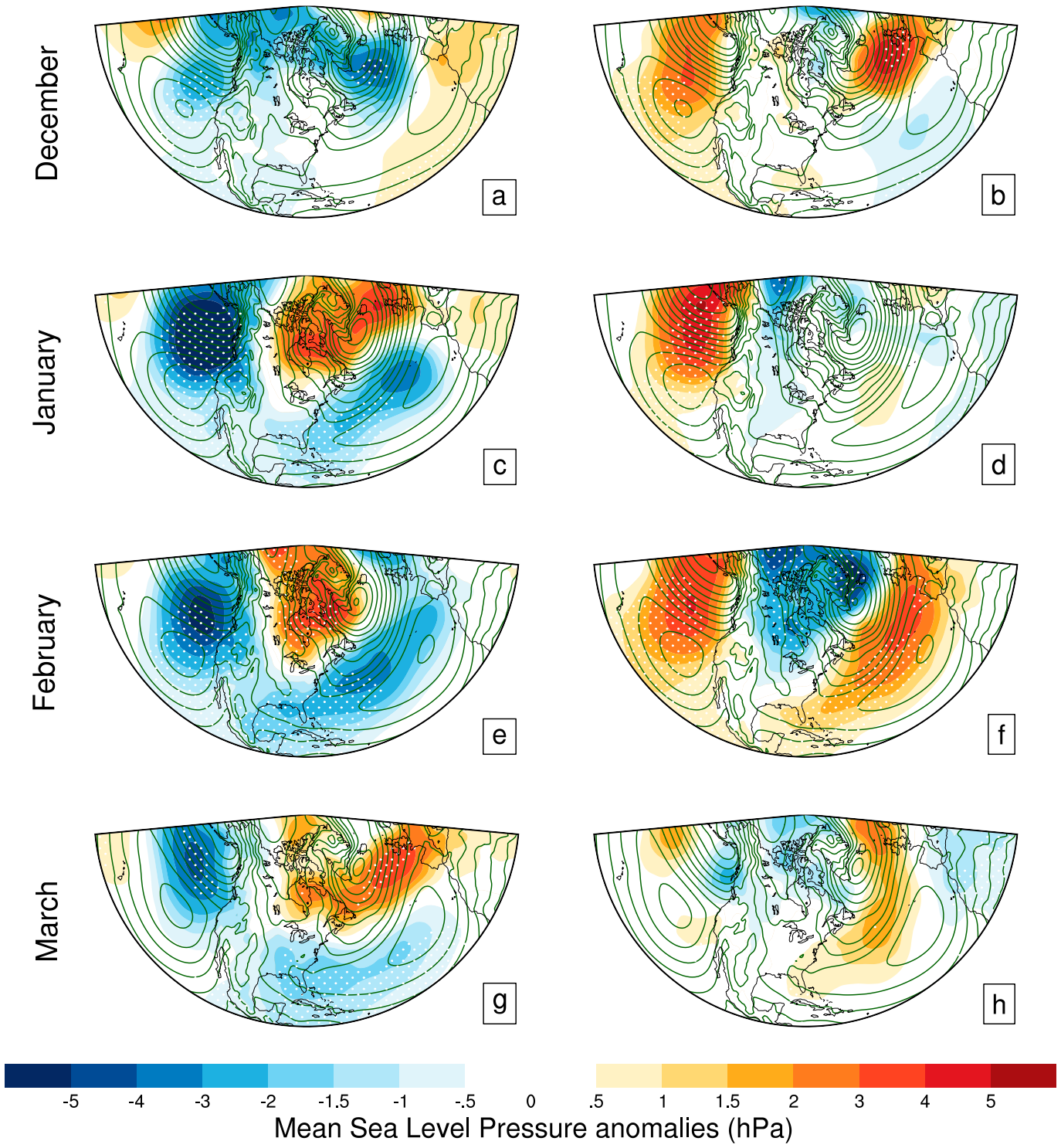

FIG. 1. Sea level pressure anomalies (shading) for December-March and for (a),(c),(e),(g) El Niño and (b),(d), (f),(h) La Niña conditions for $15^{\circ}-90^{\circ} \mathrm{N}$ and $170^{\circ} \mathrm{W}-10^{\circ} \mathrm{E}$. Green contours indicate climatological values based on the ERA-40 and ERA-Interim datasets combined (1958-2016) for each month using 2-hPa intervals, and dotted regions indicate $90 \%$ significance based on a single-tailed $t$ test.

Figure 1 shows the evolution of sea level pressure during EN and LN conditions. In the North Pacific, during EN conditions the Aleutian low is deepened and extended eastward. Almost the opposite response is seen during LN winters (i.e., a weaker Aleutian low and a northward extension of the subtropical anticyclone). Surface pressure anomalies in the North Pacific during both EN and LN usually peak between January and February. In the North Pacific the response is slightly more persistent during EN, extending well into
March, while the anomalies disappear after February during LN winters. This part of the tropospheric pathway of ENSO looks linear, in the sense that sea level pressure anomalies in the Aleutian low region correlate well with the tropical SST ENSO forcing. Note however that Frauen et al. (2014) show that this apparent linearity might be due to the interplay of several nonlinear teleconnections. This is also a stationary response (i.e., the signal in this region has the same sign throughout winter). 
In contrast, the response in the Atlantic is much more complex. A negative NAO is present from January to March during EN conditions. But the surface response is only statistically significant in the western part of the North Atlantic basin, just off the North American coast, whereas it is not significant in the eastern part. This might be related to a higher variability in the eastern North Atlantic. On the other hand, during LN conditions, a clear positive NAO tends to occur only in February, whereas no significant anomalies can be observed for the other winter months. Even though during LN the Aleutian low shows significant positive anomalies also in January, the PNA pattern lobes appear only later in February. According to, for example, Pinto et al. (2011) or Li and Lau (2012b), this could be an explanation of why the North Atlantic response only appears to be significant in February in this case.

Because of this strong variability throughout winter the signal in the North Atlantic in response to ENSO is not statistically significant when sea level pressure anomalies are seasonally averaged (DJF or JFM). This confirms results by Moron and Gouirand (2003), who also find a clear shift in the NAO phase between November-December compared to January-March using more than 100 years of the global mean sea level pressure dataset (GMSLP2; Basnett and Parker 1997). For this reason we here use monthly averages with the aim of analyzing the seasonal evolution of the anomalies.

As already discussed, the stratospheric downward influence can also play an important role inducing the NAO phase. This downward impact can be characterized by the monthly average evolution of the NAM index at each pressure level from November until April both during EN (Fig. 2a) and LN (Fig. 2b) years. Negative (positive) values of the NAM indicate a weaker (stronger) than average polar vortex at stratospheric levels and a southward (northward) shift of the jet in the troposphere. During EN a weaker than normal vortex can be observed in the upper stratosphere already in December. These anomalies propagate downward during midwinter and reach the surface from February to early spring (e.g., Calvo et al. 2017; Manzini 2009; Cagnazzo and Manzini 2009; Ineson and Scaife 2009). It is important to note that the weakest state of the polar vortex occurs in February and persists in the lower stratosphere until the spring vortex breakup. Negative values of the NAM at tropospheric levels appear already in January, likely as a result of the tropospheric pathway of EN itself. Almost the opposite can be stated for LN winters; that is, a stronger than normal vortex is observed from November to February, with a peak in February [comparable results to Iza et al. (2016)]. However, a weaker than normal vortex can be observed in late winter (March), which could be related to an earlier than normal final warming.

\section{Quasi-stationary and transient wave propagation under ENSO control}

Our next step is to analyze the physical mechanisms responsible for this circulation response in the Atlantic. Using the formulation described in section 2 we are now able to define wave propagation indices based on the zonal component of the WAF from the North Pacific to the North Atlantic. We define the $F$ index as the zonal component of the quasi-stationary WAF $F_{x}$ integrated over North America $\left(120^{\circ}-60^{\circ} \mathrm{W}, 40^{\circ}-60^{\circ} \mathrm{N}\right)$ at the 250-hPa level. Choosing other tropospheric levels or integrating across several levels leads to comparable results. In the same way, we define the $M$ index as the zonal component of transient WAF $M_{x}$ integrated over a region $20^{\circ}$ farther south $\left(120^{\circ}-60 \mathrm{~W}, 20^{\circ}-40^{\circ} \mathrm{N}\right)$ and at the same level, as these eddies tend to climatologically propagate farther south. We compute these one-dimensional WAF indices using the daily time resolution of the zonal components of the WAF. Then monthly averages for January, February, and March are computed and the time series are standardized. Finally, individual months with a value of the WAF above 1.5 standard deviations are selected for the composite.

Figure 3 shows sea level pressure and geopotential height anomalies at 250 and $50 \mathrm{hPa}$ associated with strong eastward propagation of transients and QS waves. These events are WAF pulses that take place on weekly to monthly time scales. We therefore select individual months in the winter season that exhibit a strong zonal propagation of waves independent of the ENSO phase.

Downstream propagation of transient eddies ( $M$ index $>1.5$ standard deviations) is enhanced during months with a deeper Aleutian low (Figs. 3a,b). At the east coast of the North American continent, in the Atlantic a clear negative NAO pattern emerges. This clearly suggests that the downstream propagation of transient eddies from one basin to the other is a very probable mechanism to establish this link, as shown before by Li and Lau (2012b). On the other hand, the stationary wave pattern for the strong QS wave propagation ( $F$ index $>1.5$ standard deviations) exhibits a different response in the North Atlantic, which might be related to Atlantic blocking [i.e., the east Atlantic (EA) pattern; Barnston and Livezey 1987]. As suggested by Egger (1978), stationary wave trains might be linked to 
(a) El Niño

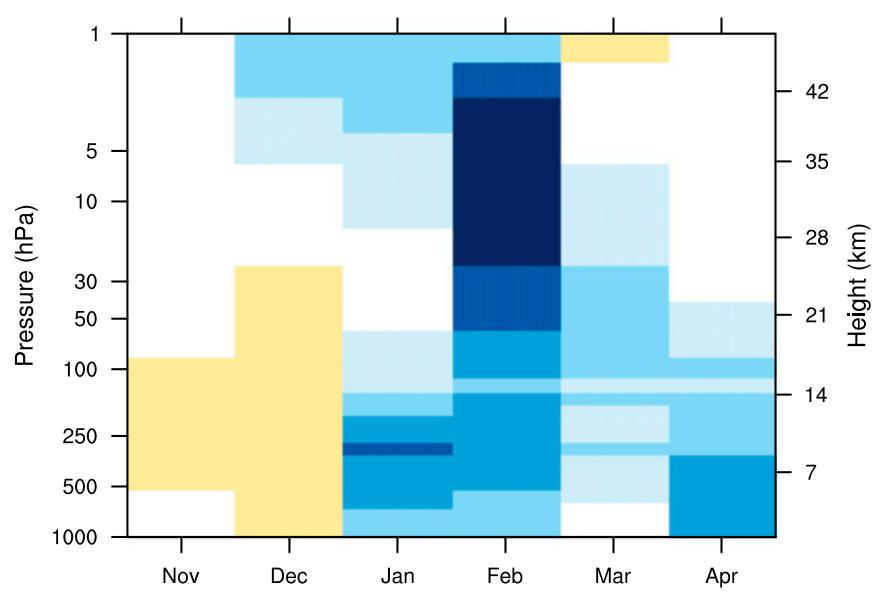

(b) La Niña

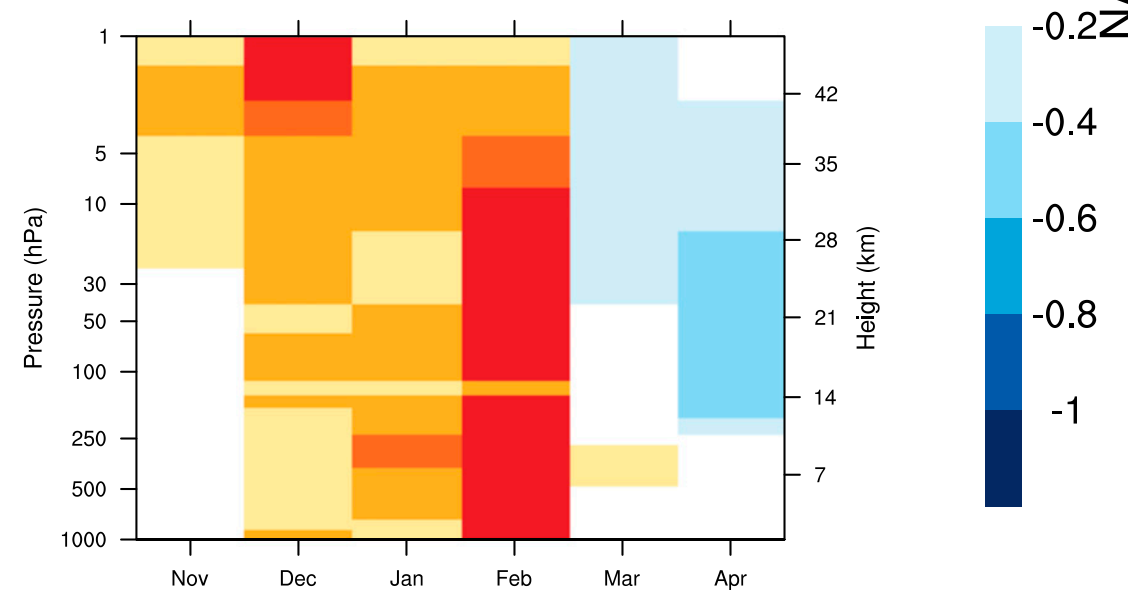

FIG. 2. NAM index monthly composite for November-April and for (a) El Niño and (b) La Niña conditions using the one standard deviation threshold for ENSO. The index is computed independently at each pressure level using monthly geopotential anomalies. Negative (positive) values are indicative of a weaker (stronger) vortex in the stratosphere and a southward (northward) shift of the jet in the troposphere.

most of the blocking events in the extratropical regions. Note that the Pacific signature for this type of event differs from the transient eddies composite, with a southward-shifted negative SLP anomaly and a high pressure anomaly in NW Canada.

Note that the majority of extreme transient WAF events occurs in the period of the reanalysis covered by ERA-Interim (i.e., after 1978, not shown). This absence of extreme transient propagation events in the first period could be related to a weakened manifestation of the Icelandic-Aleutian low seesaw (Honda et al. 2005b) or the weakened PNA-NAO linkage (Pinto et al. 2011). The origin of this decadal variability is still not fully understood. In connection with this, Greatbatch (2004) find that the ENSO signal in the NAE region is weaker during 1958-77 as compared to 1979-97. This agrees well with our results, in fact we will show that transient eddies play a major role delivering the ENSO signal to the NAE sector in the next section.

Focusing on the QS waves, we investigate whether different zonal wavenumbers may have different associated circulation anomalies in these regions. We filter the temperature and geopotential height field anomalies by zonal wavenumber, separating out the signal from wavenumbers 1 to 3 (Figs. $3 \mathrm{~g}-\mathrm{i}$ ). Comparing these anomalies with the QS waves using the full field (Figs. 3d-f) indicates that a strong WAF of small wavenumbers is linked to a high pressure system in the 

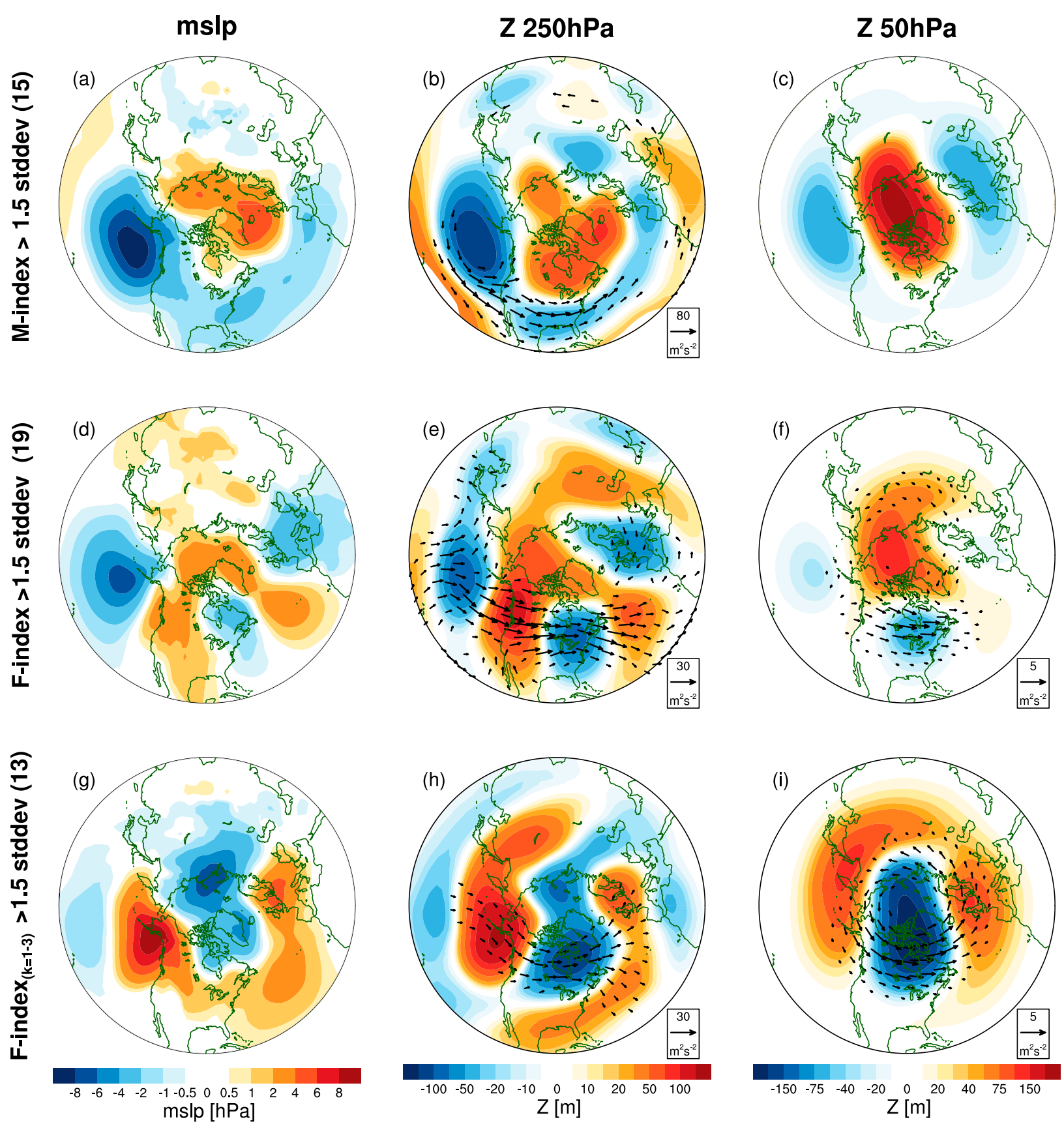

FIG. 3. Composites of (left) anomalous mean sea level pressure and geopotential height at (center) 250 and (right) $50 \mathrm{hPa}$, averaged over individual January, February, and March months when there is a strong propagation of (a) $-(\mathrm{c})$ transient eddies $(M$ index $>1.5$ standard deviations), (d)-(f) QS waves ( $F$ index $>1.5$ standard deviations), and (g)-(i) only small-wavenumber QS waves $(F$ index $k=1-3>1.5$ standard deviations). Vectors indicate anomalous horizontal transient eddy propagation $\left(M_{x}, M_{y}\right)$ at $250 \mathrm{hPa}$ in (b) and QS wave propagation $\left(F_{x}, F_{y}\right)$ at the troposphere in (e) and (h) and at the lower stratosphere in (f) and (i). The number in brackets indicates the number of cases for each composite. Of these, 5 occur in January, 7 in February, and 3 in March in (a)-(c); 11 occur in January and 8 in February in (d)-(f); and 5 occur in January and 8 in February in (g)-(i).

Gulf of Alaska and a positive NAO pattern in the North Atlantic region.

Figure 4 shows the longitude-height cross section of the stationary WAF averaged over $40^{\circ}-70^{\circ} \mathrm{N}$. Enhanced quasi-stationary eastward wave propagation over North America originates near the surface and propagates upward and northward in the North Pacific region $\left(150^{\circ} \mathrm{W}\right)$ (Fig. 4a). When these waves reach the tropopause, most 
(a) all Wavenumbers [40-70N]

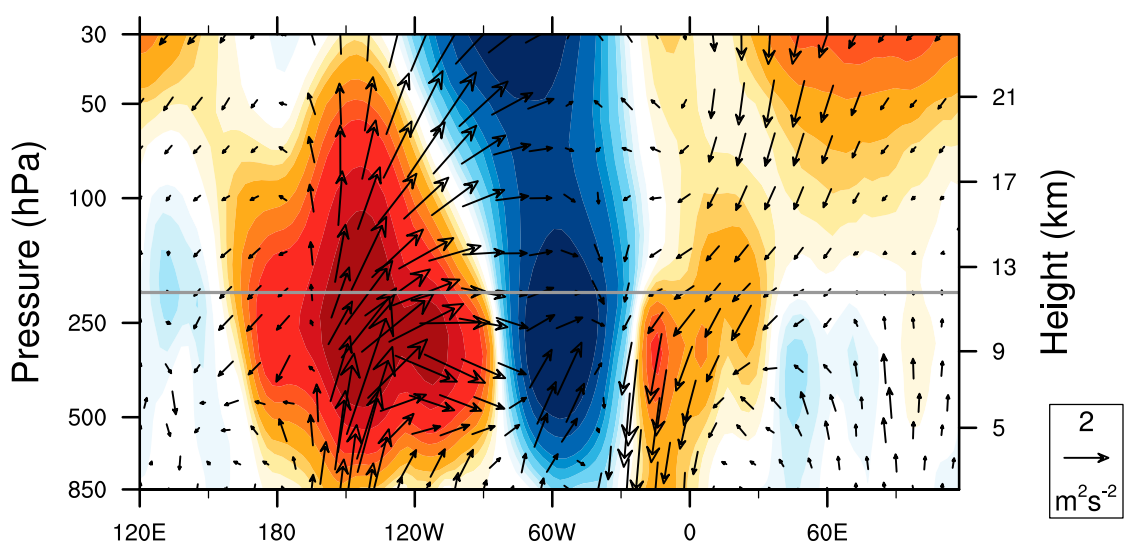

(b) Small wavenumbers $(\mathrm{k}=1-3)[40-70 \mathrm{~N}]$

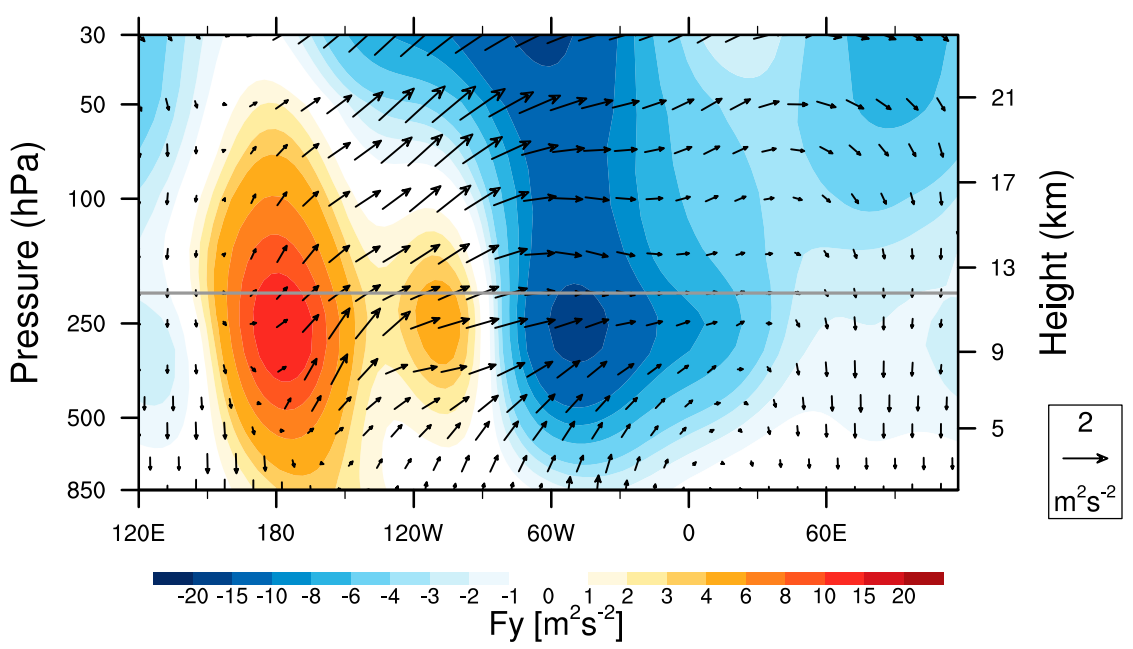

FIG. 4. Height-longitude cross section of the composites in Fig. 3 averaged over $40^{\circ}-70^{\circ} \mathrm{N}$ for (a) all QS waves and (b) long QS waves. Vectors show the $\left(F_{x}, F_{z}\right)$ of the WAF, and color shading indicates the meridional component $F_{y}$ of the WAF. Vector components are scaled before plotting using $F_{x}^{s}=F_{x} \times(2 \pi a \cos \phi)^{-1}\left(p_{s} / p\right) \times 10^{6} ; F_{z}^{s}=F_{z} \times H_{s}^{-1}\left(p_{s} / p\right) \times 10^{6}$; and $F_{y}^{s}=F_{y}\left(p_{s} / p\right)$, where $p_{s}=1013 \mathrm{hPa}$ is the mean sea level pressure, $a=6370 \mathrm{~km}$ is Earth's radius, and $H_{s}=50 \mathrm{~km}$ is a scale factor for the vertical coordinate.

of them tend to propagate eastward, coherent with the definition of our index of eastward WAF anomalies over North America at $250 \mathrm{hPa}$. When the waves reach the Atlantic region $\left(90^{\circ} \mathrm{W}\right)$, they bend south giving rise to the geopotential tropospheric anomalies observed in Fig. 3. Interestingly there is also an upward source of wave activity in the Atlantic, typically associated with the Atlantic storm track (PB85).

The behavior of long waves (Fig. 4b) is different, as expected from the previous analysis. The source of this type of wave in the Pacific is above $500 \mathrm{hPa}$ and not at the surface as for the smaller wavenumbers. Small-wavenumber QS waves are able to propagate higher according to the Charney-Drazin criterion
(Charney and Drazin 1961). In the lower stratosphere (around $100 \mathrm{hPa}$ ) anomalous downward propagation is observed, associated with strong vortex conditions (see Figs. 3f,i).

But how do these indices change with respect to ENSO? To answer this question we show the daily histograms for the wave fluxes during EN and LN conditions for January-March (Fig. 5). A clear increase in eastward-propagating transient eddies is observed during EN compared to LN conditions, which is shown to be statistically significant according to a random sampling of a Kolmogorov-Smirnov test ( $p$ value $<10^{-3}$ ). On the other hand, no shift can be observed for the unfiltered quasi-stationary waves, and the difference in 
(a) Transient

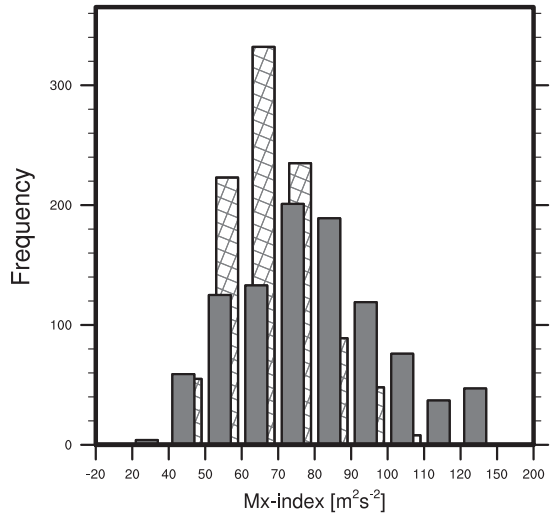

(b) Quasi-stationary

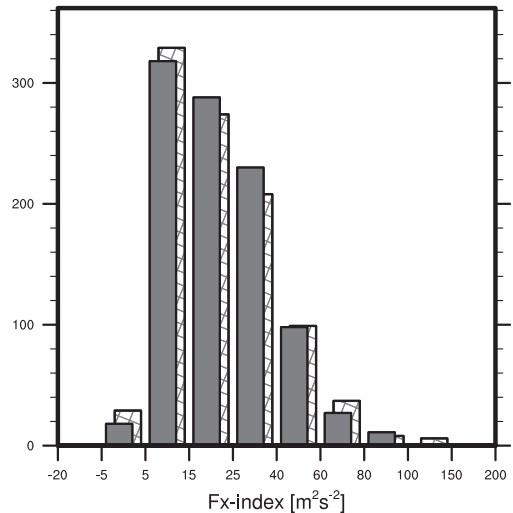

(c) Quasi-stationary ( $\mathrm{k}=1-3)$

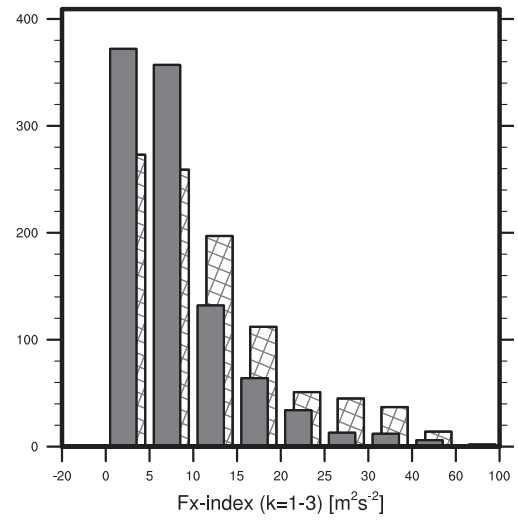

FIG. 5. Histograms of (a) the transient WAF index ( $M$ index) and the QS WAF index ( $F$ index) for (b) all wavenumbers and (c) for small wavenumbers $(k=1-3)$ of El Niño (shaded bars) and La Niña (stippled bars). We use 11 winters for each ENSO phase, each winter consisting of 90-91 days, from 1 Jan to 31 Mar.

the distributions is not statistically significant. The same is true when limiting the wave spectrum of QS waves to $k=4-8$ (not shown). In contrast, for small wavenumbers $(k=1-3)$ an increase is observed during LN conditions with respect to EN. This difference is statistically significant, with a $p$ value $\sim 10^{-3}$.

It is also interesting to investigate the seasonal dependence of the propagation (Fig. 6). Both transient and quasi-stationary waves have an eastward propagation peak in midwinter, February for transients and January for QS (see upper 90th percentile in Figs. 6a,b). The time peak is broader for transient eddies, with a more or less smooth evolution throughout winter. Comparing the full wavenumber spectrum to small wavenumbers $(k=1-3)$, a different behavior can be observed [i.e., a sharper peak shifted to late winter (February)].

When addressing the question of the seasonal evolution dependence on ENSO, the colored lines confirm our previous findings using histograms: there is a clear increase in eastward-propagating transient eddies during EN winters and a decrease during $\mathrm{LN}$, most importantly in January and February. With respect to QS waves, the results also corroborate our previous findings: a significant positive (negative) eastward propagation anomaly of long QS waves $(k=$ $1-3$ ) is observed during LN (EN) conditions in mid-tolate winter. LN positive anomalies are more pronounced in February, but a clear decrease is observed (a) Transient

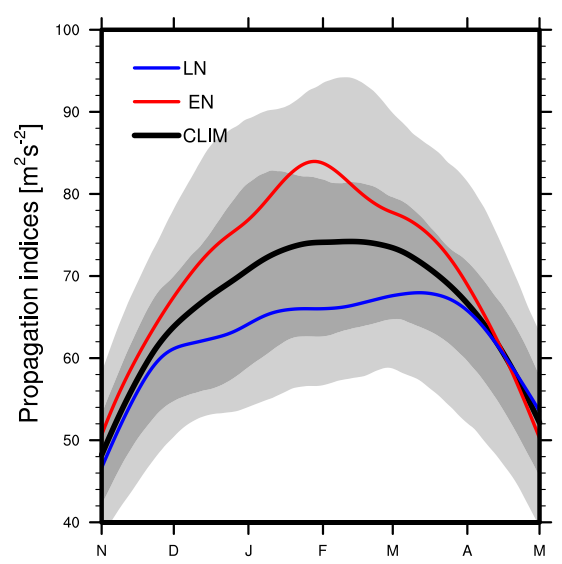

(b) Quasi-stationary

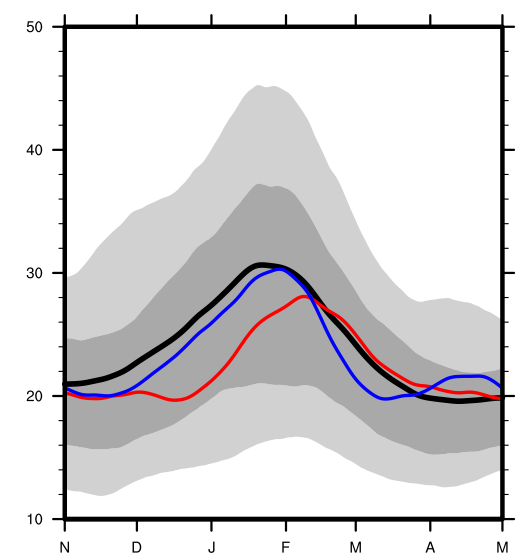

(c) Quasi-stationary ( $k=1-3)$

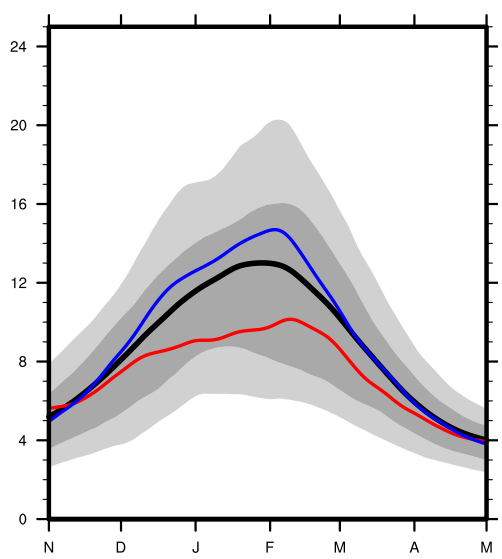

FIG. 6. Seasonal daily mean evolution of (a) the transient WAF index ( $M$ index) and the QS WAF index $(F$ index) for $(b)$ all wavenumbers and (c) for only small wavenumbers $(k=1-3)$. Shown are climatology (black line), El Niño (red), and La Niña (blue) mean values. A 30 -day running mean is applied before computing calendar daily climatological means. The dark (light) gray shaded region indicates the 10 th, 25th, 75th, and 90th percentiles, respectively. 
for EN throughout winter. Figure $6 \mathrm{~b}$ shows a decrease of eastward WAF of the full spectrum of QS waves in early winter (from December to January) during EN years; this could seem to be contradicting what we observe in the daily change of the WAF (Fig. 5b), where we cannot see a shift in the distributions between the two phases of ENSO for the January-March period. However, the mean seasonal evolution during February-March shows the opposite sign (Fig. 6b) counteracting the early winter anomaly and making the sensitivity to ENSO of the full spectrum of QS waves not robust throughout the winter.

In summary, transient eddies propagate anomalously eastward across North America during EN winters, whereas small-wavenumber QS waves propagate anomalously eastward from the North Pacific to the North Atlantic during LN conditions. In contrast, no significant shift is seen when considering the full spectrum of QS waves.

\section{The ENSO-North Atlantic tropospheric teleconnection}

In this section we analyze the ENSO impact on the North Atlantic region linking changes of WAF with the circulation anomalies in the upper troposphere. Figure 7 shows ENSO-based composites of transient and QS WAF, along with geopotential height and zonal wind anomalies in the upper troposphere $(250 \mathrm{hPa})$ during late winter (January-March). As discussed previously, composites in this section consist of 11 events both for EN and LN. In this section quasi-stationary waves refer to small wavenumbers $(k=1-3)$ as these have been shown to exhibit a significant sensitivity to the state of ENSO. Larger wavenumbers may also have a small but nonsignificant contribution. Moreover, wavenumbers 1-3 also are linked to the NAO pattern and to the observed largescale anomalies (Figs. 3g,h).

During EN winters, a deeper than normal AL is associated with a southward shift of the subtropical jet (zonal wind anomaly dipole) (Figs. 7a-f). These anomalies extend eastward toward the North American and North Atlantic sectors (mainly in January and February and to a smaller extent in March) (Figs. 7a-c). Associated with a southward shift of the Pacific tropospheric jet (Figs. 7d-f), transient eddies propagate farther south in the Pacific and penetrate into the west Atlantic region (Figs. 7a-c). This is not the case in March, when there are anomalous westward-propagating transient eddies in the North Atlantic. It is important to note that transient eddies tend to propagate anomalously eastward at the location of the negative geopotential anomalies, both being related to the storm-track position. For QS waves, the opposite behavior can be observed during EN conditions (i.e., anomalous westward propagation), meaning less propagation from the North $\mathrm{Pa}$ cific to the Atlantic.

In general the LN pattern is close to opposite of the EN pattern, despite some asymmetries with respect to EN (Feng et al. 2017; Zhang et al. 2014). It consists of a northward shift of the Pacific tropospheric jet (Figs. 7j-1) and a weaker than normal Aleutian low in the North Pacific (Figs. 7g-i). Consistent with this anomaly, less propagation (westward anomalies) of transient eddies in the southern part of North America is observed. In February the geopotential height anomalies resemble the negative phase of the NAO, coinciding with the only month when the QS WAF is anomalously eastward from the Alaskan peninsula to the North Atlantic (Fig. 7k). The Rossby wave train exhibits a northeast-southwest direction, and the 3D WAF divergence (convergence) (not shown) matches the positive (negative) anomalies of the upper troposphere zonal wind.

We also study how the baroclinicity responds to these circulation changes. Figure 8 shows the late winter monthly evolution of the maximum EGR integrated from 900 to $300 \mathrm{hPa}$, as a measure of the baroclinic instability (i.e., the potential location of synoptic baroclinic eddy generation). The southward shift of the subtropical jet is associated with a general southward shift of the baroclinicity during EN events (Figs. 8a-c). These anomalies are indeed associated with the geopotential height anomalies at $500 \mathrm{hPa}$ (contour lines in the same plot). This indicates a positive feedback: synoptic-scale eddies have a tendency to form in the regions below the subtropical jet, where the vertical wind shear enhances baroclinicity, thus contributing to maintain geopotential tropospheric anomalies (Lorenz and Hartmann 2001). Not surprisingly the response is almost antisymmetric during LN winters (Figs. 8d-f). However, in February during LN, baroclinicity anomalies are stronger in the North Atlantic, coinciding with a clear positive NAO.

Figure 9 shows the geopotential height tendency induced by transient eddies. During EN the deepening of the AL in January is dominantly contributed by transient eddies, as seen by the matching of the negative geopotential contours and the negative tendency of the eddy feedback (in blue). Later in February most of the forcing is moved to the east coast of North America and the west Atlantic. Anomalies of the feedback start to fade away in March when this feedback is less important. In contrast, $\mathrm{LN}$ winters show a signal that is close to the 

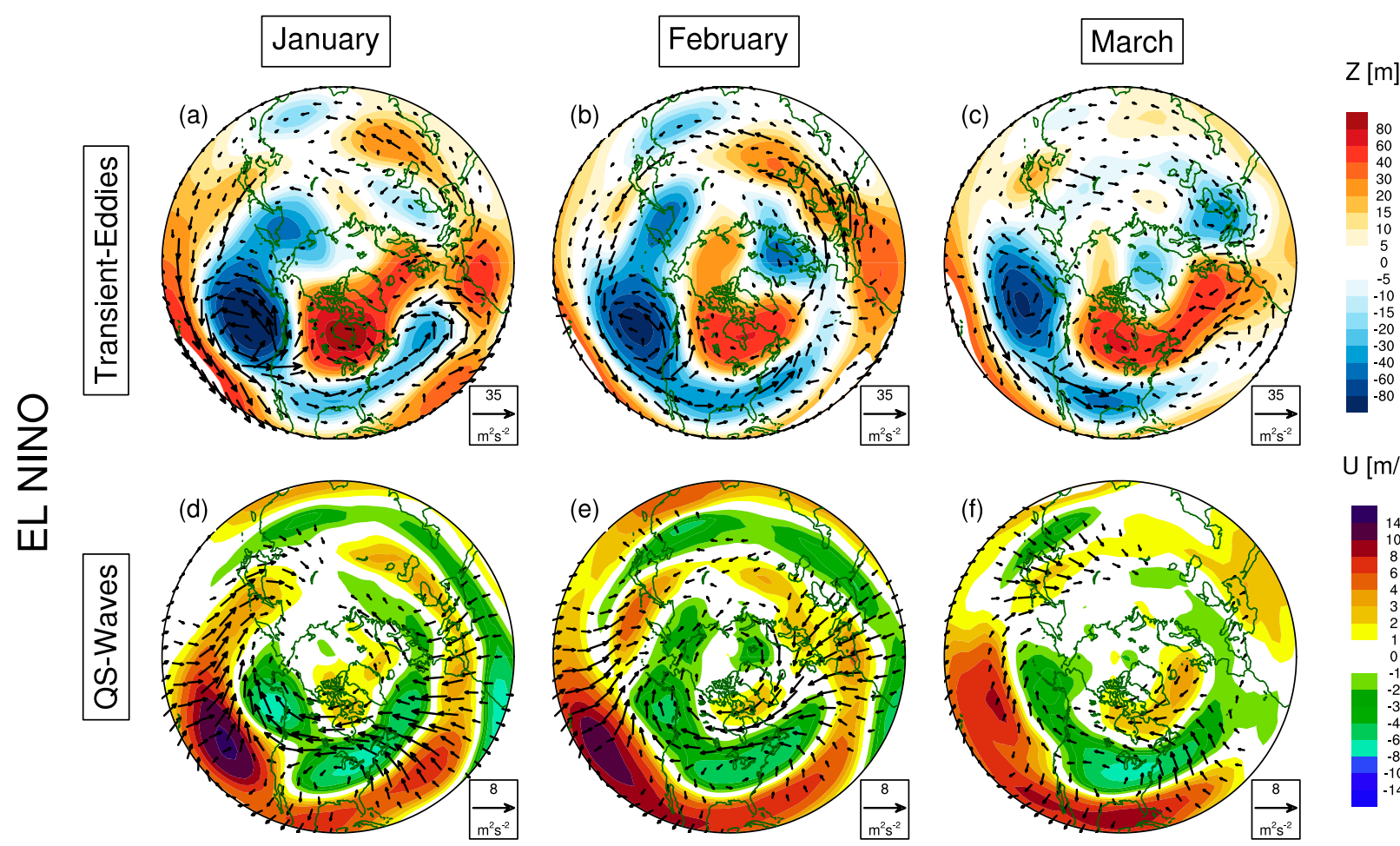

$\mathrm{U}[\mathrm{m} / \mathrm{s}]$
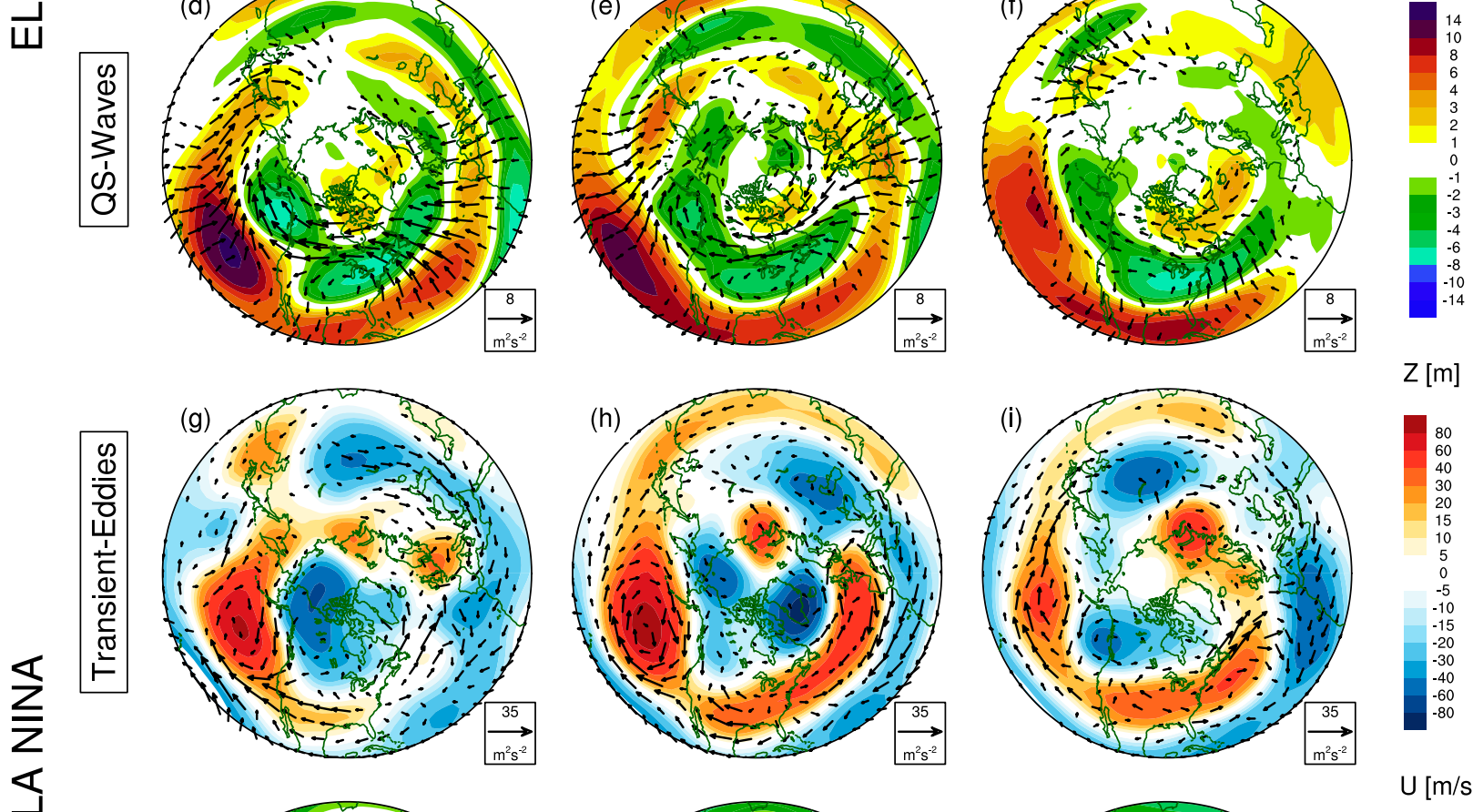

$\mathrm{Z}[\mathrm{m}]$
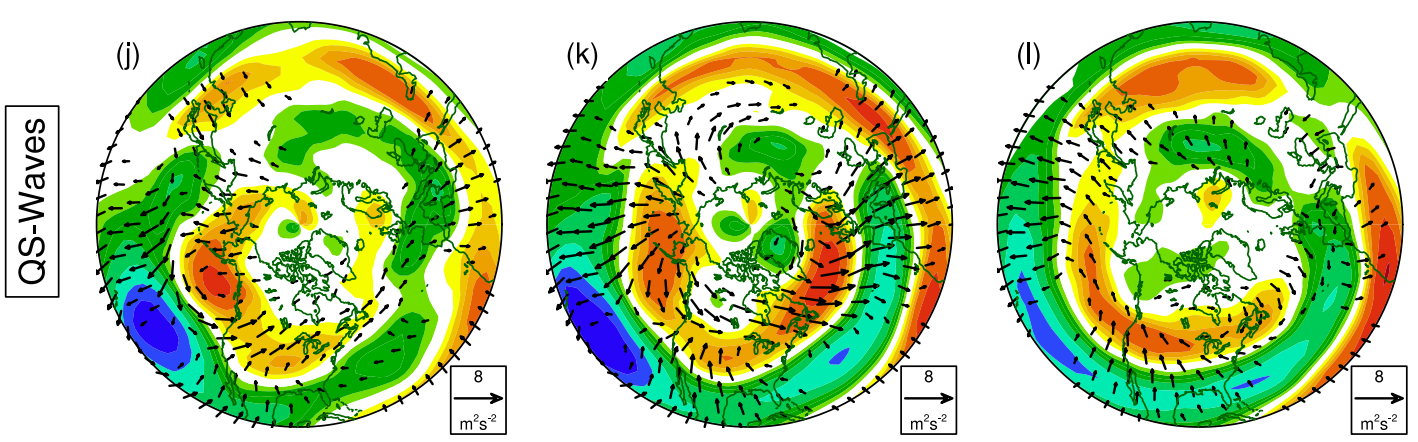

$\mathrm{U}[\mathrm{m} / \mathrm{s}]$

FIG. 7. Composites of anomalous transient horizontal WAF vectors and geopotential height anomalies (color shading) at $250 \mathrm{hPa}$ during (a)-(c) EN and (g)-(i) LN winters. As in (a)-(c) and (g)-(i), but for QS WAF vectors $(k=1-3)$ and zonal wind anomalies for (d)-(f) EN and (j)-(l) LN.

opposite pattern. In this case synoptic transient eddies contribute to the formation of negative geopotential anomalies in Iceland, while the southern positive anomalies are to a smaller extent responsible for the transient eddy forcing. We speculate that this part of the LN response is mainly driven by the long QS wave train observed in Fig. 7k. To summarize, transient eddies play an important role for maintaining and intensifying the 

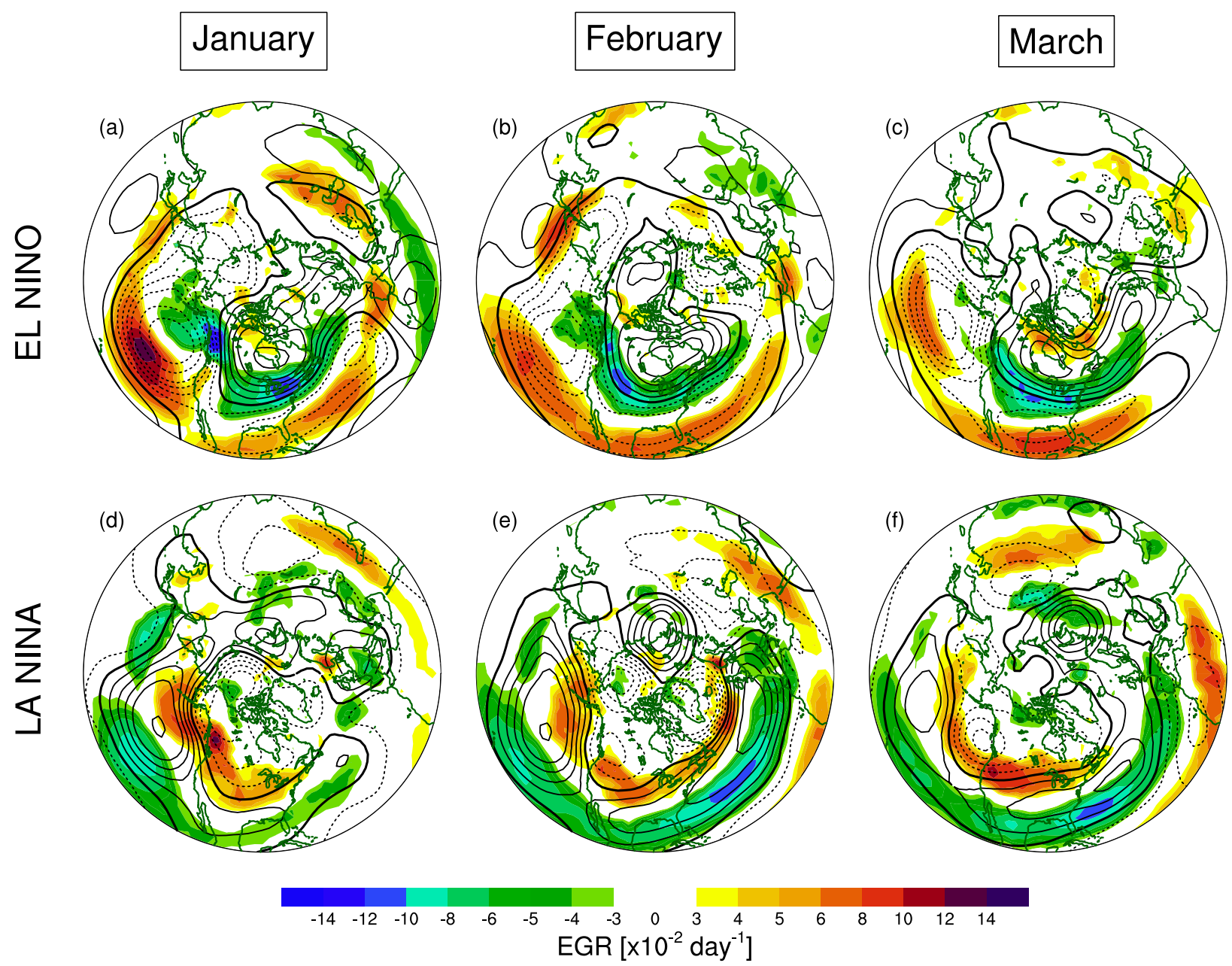

FIG. 8. Composites of anomalies of vertically integrated EGR from 900 to $300 \mathrm{hPa}$ (shaded regions) from January to March for (a)-(c) EN and (d)-(f) LN conditions. Contours represent geopotential height anomalies at $500 \mathrm{hPa}$, and negative values are dashed.

North Atlantic NAO response, in particular during EN winters.

\section{Separating the stratospheric pathway}

Since stratospheric anomalies have a clear influence on the wintertime tropospheric circulation, the tropospheric pathway of ENSO to the North Atlantic could be significantly modified depending on the state of the stratosphere. Here we assess the stratospheric influence on the described tropospheric processes and how the circulation response in the troposphere is affected. We divide each ENSO phase into strong, weak, and neutral polar vortex winters (see section 2).

Figure 10 shows JFM anomalies of geopotential and zonal wind together with transient and QS WAF horizontal vectors for different ENSO phases and stratospheric polar vortex classifications. Focusing first on EN (Figs. 10a-f), the geopotential height response varies significantly with the vortex mean strength. In particular, in the North Pacific the usual deepened Aleutian low is substituted by an anomalous ridge during strong polar vortex events (Fig. 10a). These events are not very common, only 4 years out of the 58 considered; however, this indicates a high variability from one EN event to another. In contrast, a clear negative NAO is observed during EN and weak polar vortex events (5 events) (Fig. 10b), also associated with a negative tropospheric NAM, which corresponds to the typical stratospheretroposphere downward coupling response after SSW events (Baldwin and Dunkerton 2001). QS waves propagate anomalously westward in this case (Fig. 10e), suggesting that most of the long waves have propagated upward into the stratosphere instead of eastward, hence weakening the polar vortex. This fact demonstrates that the decrease in the eastward propagation of QS waves ( $k=1-3)$ observed in Fig. 6 mainly happens during the weakened mean state of the polar vortex during EN. 

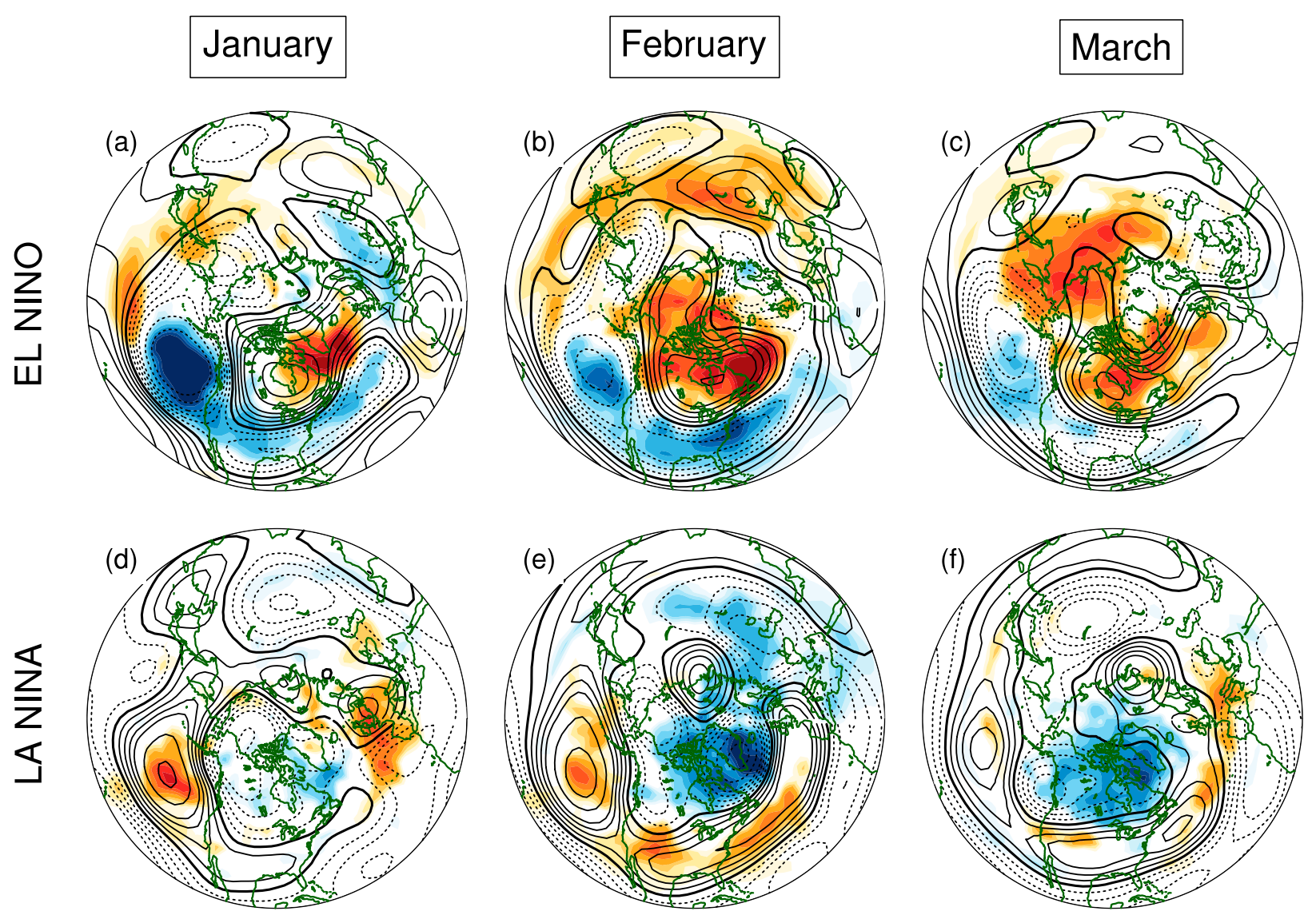
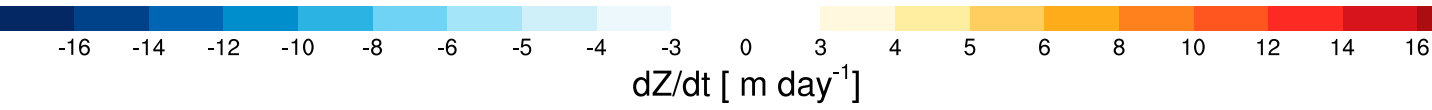

FIG. 9. Composites of anomalies of geopotential height tendency forced by transient eddies at $250 \mathrm{hPa}$ (shaded regions) from January to March for (a)-(c) EN and (d)-(f) LN conditions. Contours represent geopotential height anomalies at $250 \mathrm{hPa}$, and negative values are dashed.

Finally, neutral years exhibit a stronger shift of the tropospheric jet in the Pacific extending to North America and the western part of the North Atlantic. This shift is also related to an enhanced eastward propagation of transient eddies (Fig. 10c), in contrast with the nonsignificant response of the QS waves (Fig. 10f). From this last point we can say that QS wave propagation during EN is strongly influenced by the state of the stratosphere, while transient eddies depend on the deepening of the AL and a southward shift of the jet. We expect that for using a higher threshold for EN a stronger tropospheric response for ENSO could be observed (i.e., transient eddies propagate farther east).

The influence of the stratosphere on the LN teleconnection is shown in Figs. 10g-l. During strong vortex events a clear negative PNA pattern associated with a stronger than normal QS wave train emerges. Linked with this is a northward shift of the tropospheric jet, which elongates from the Pacific to the Atlantic sector. Downstream propagation of transient eddies across North America is reduced (westward anomalies). However, there is a small increase in the eastward transient WAF in the Newfoundland region, which is in agreement with Pinto et al. (2011). Weak polar vortex events during $\mathrm{LN}$ again show a positive geopotential height anomaly in the Aleutian low region, but this time also negative anomalies in the Bering Sea, which is a precursor zone for SSW occurrence according to Garfinkel et al. (2012). As during weak vortex conditions during EN, fewer planetary-scale waves propagate across North America (westward anomalies in the QS WAF). In the North Atlantic there is no clear response, as a weak stratospheric vortex event destructively interacts with the oppositesigned anomalies of the tropospheric LN. Finally, during neutral vortex events, we see a less clear picture 

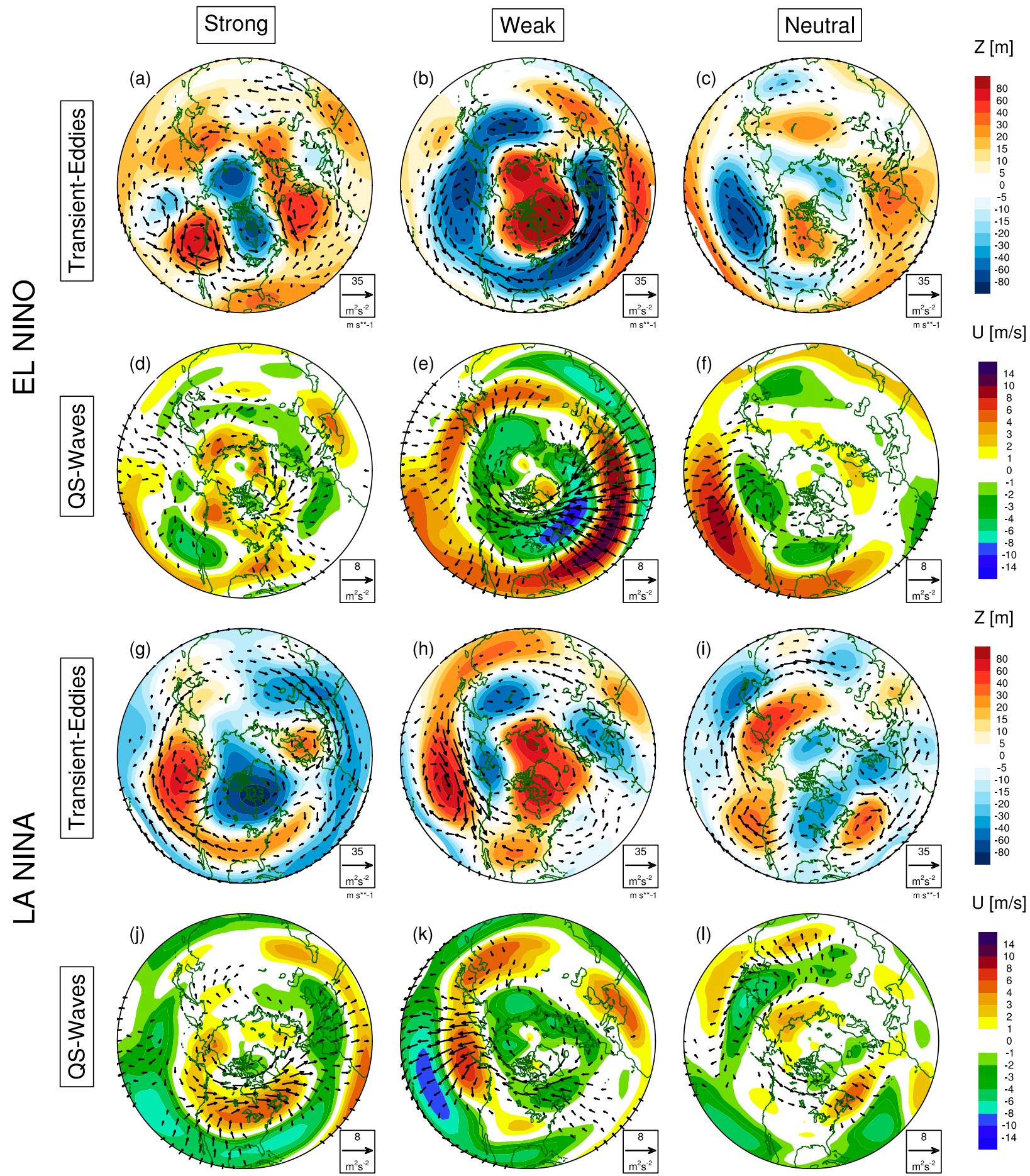

$\mathrm{Z}[\mathrm{m}]$
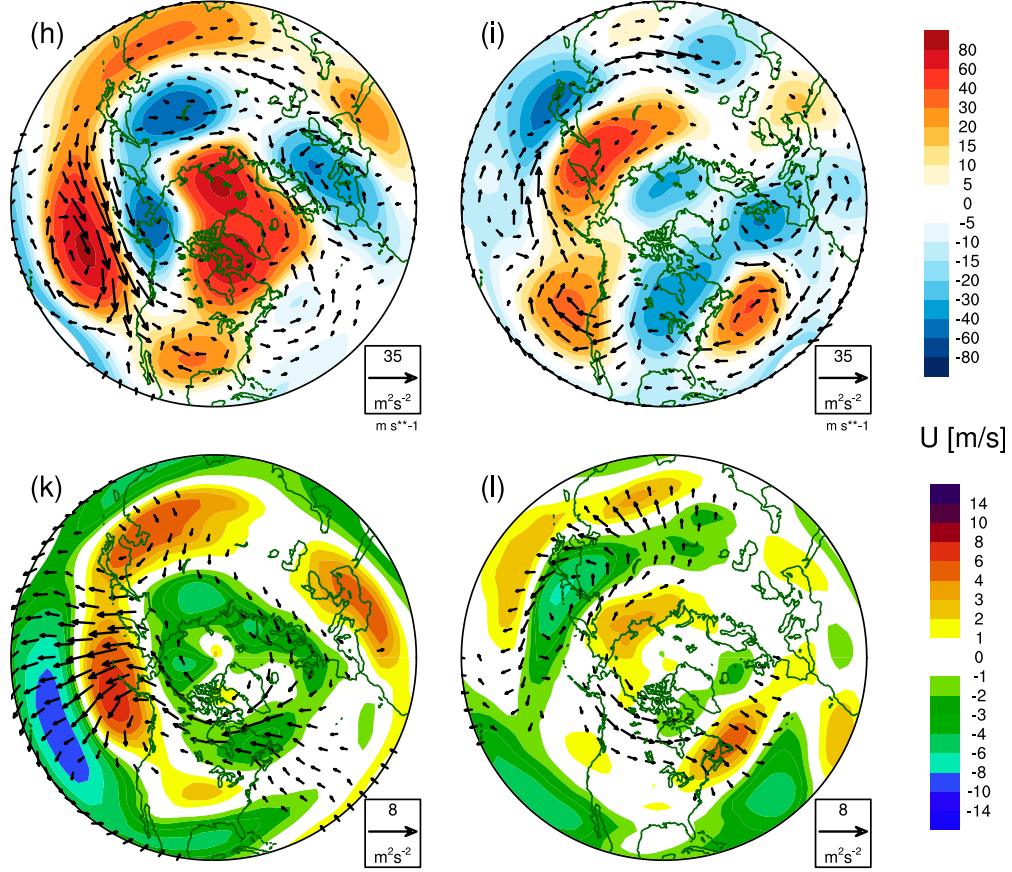

FIG. 10. As in Fig. 7, but for JFM means and different stratospheric polar vortex strengths. (a),(d),(g),(i) Strong vortex, (b),(e),(h),(k) weak vortex, and (c),(f),(i),(l) neutral stratosphere winters. Weaker ENSO events (using the 0.5 standard deviation threshold) are also considered here to separate between the different mean vortex strengths. Table 1 indicates the exact number of samples considered in each composite.

in the geopotential height anomalies. QS wave propagation is enhanced, associated with a northward shift of the tropospheric jet in the Atlantic basin, which is likely linked to a positive surface NAO. In conclusion, the LN North Atlantic teleconnection is highly dependent on the state of the stratospheric polar vortex, as QS propagation to the Atlantic is shown to highly depend on it. 

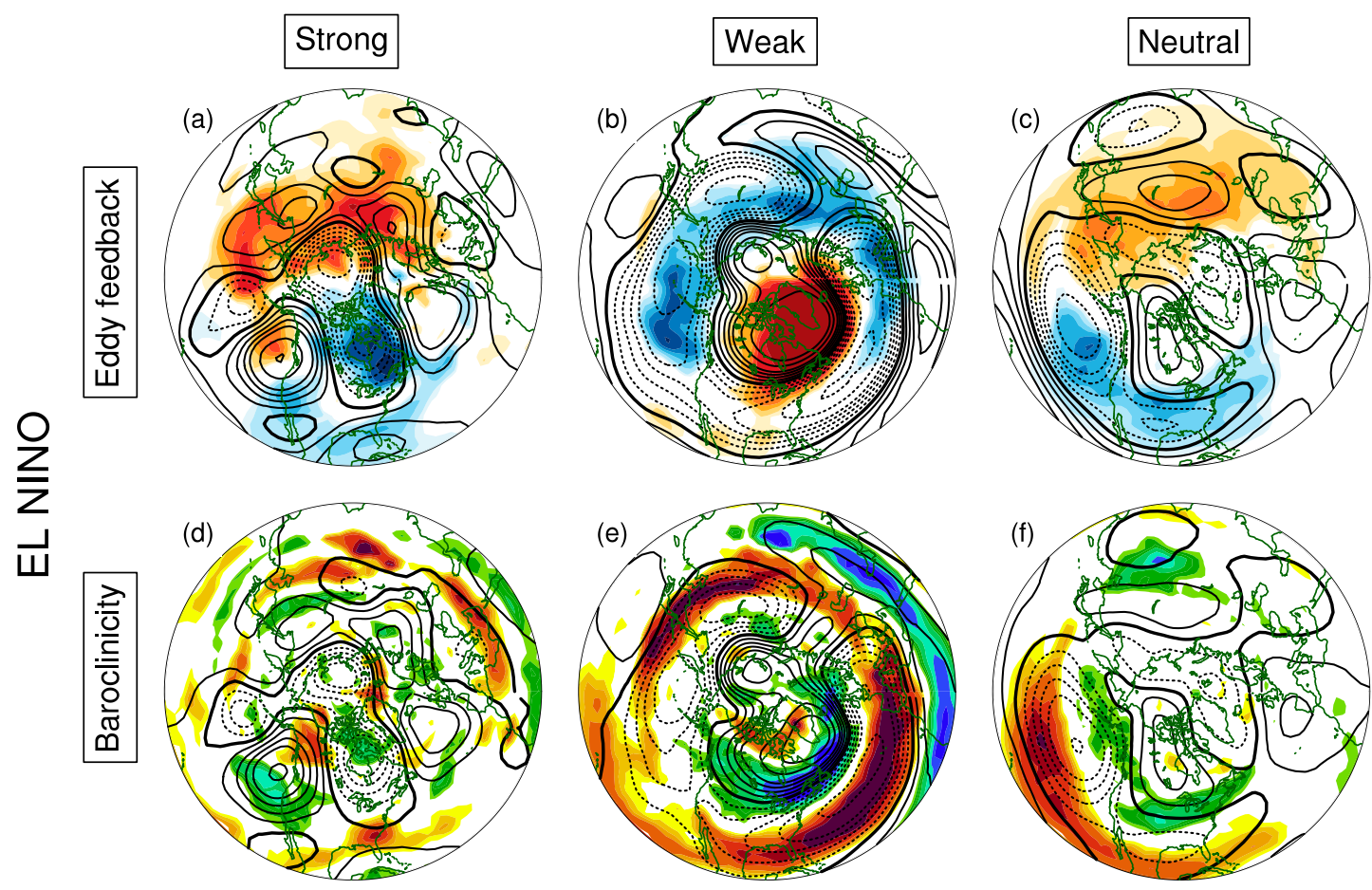

$\mathrm{dZ} / \mathrm{dt}\left[\mathrm{m}\right.$ day $\left.^{-1}\right]$
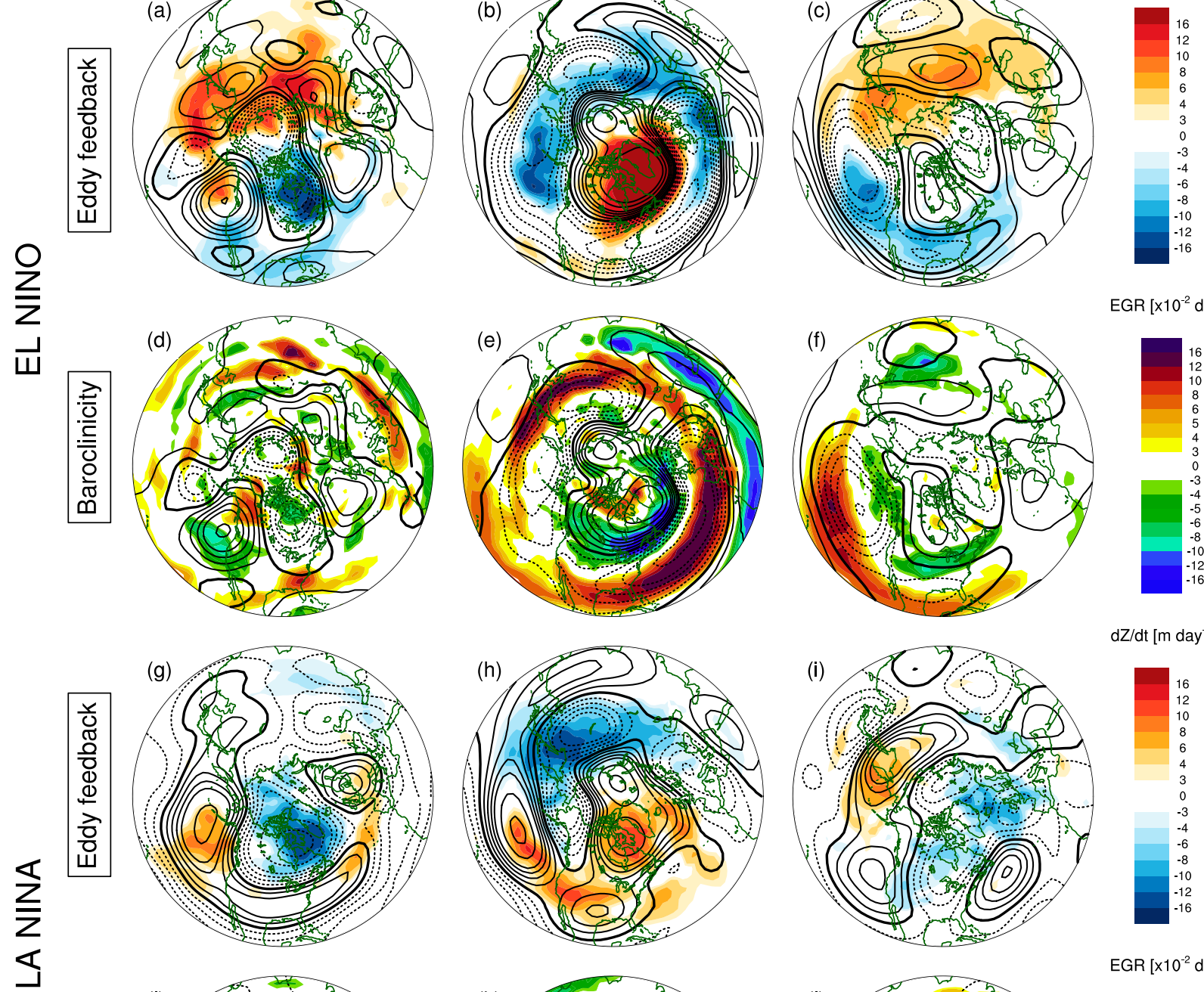

$\operatorname{EGR}\left[\times 10^{-2}\right.$ day $\left.^{-1}\right]$
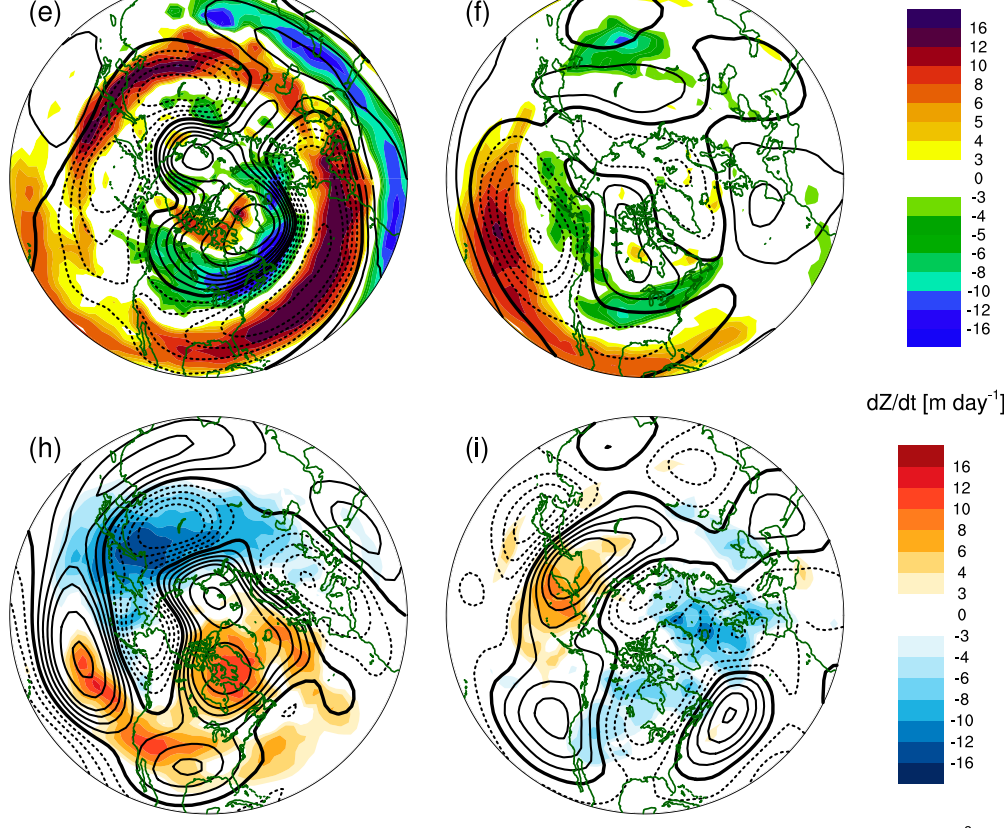

$\mathrm{dZ} / \mathrm{dt}\left[\mathrm{m}\right.$ day $\left.^{-1}\right]$
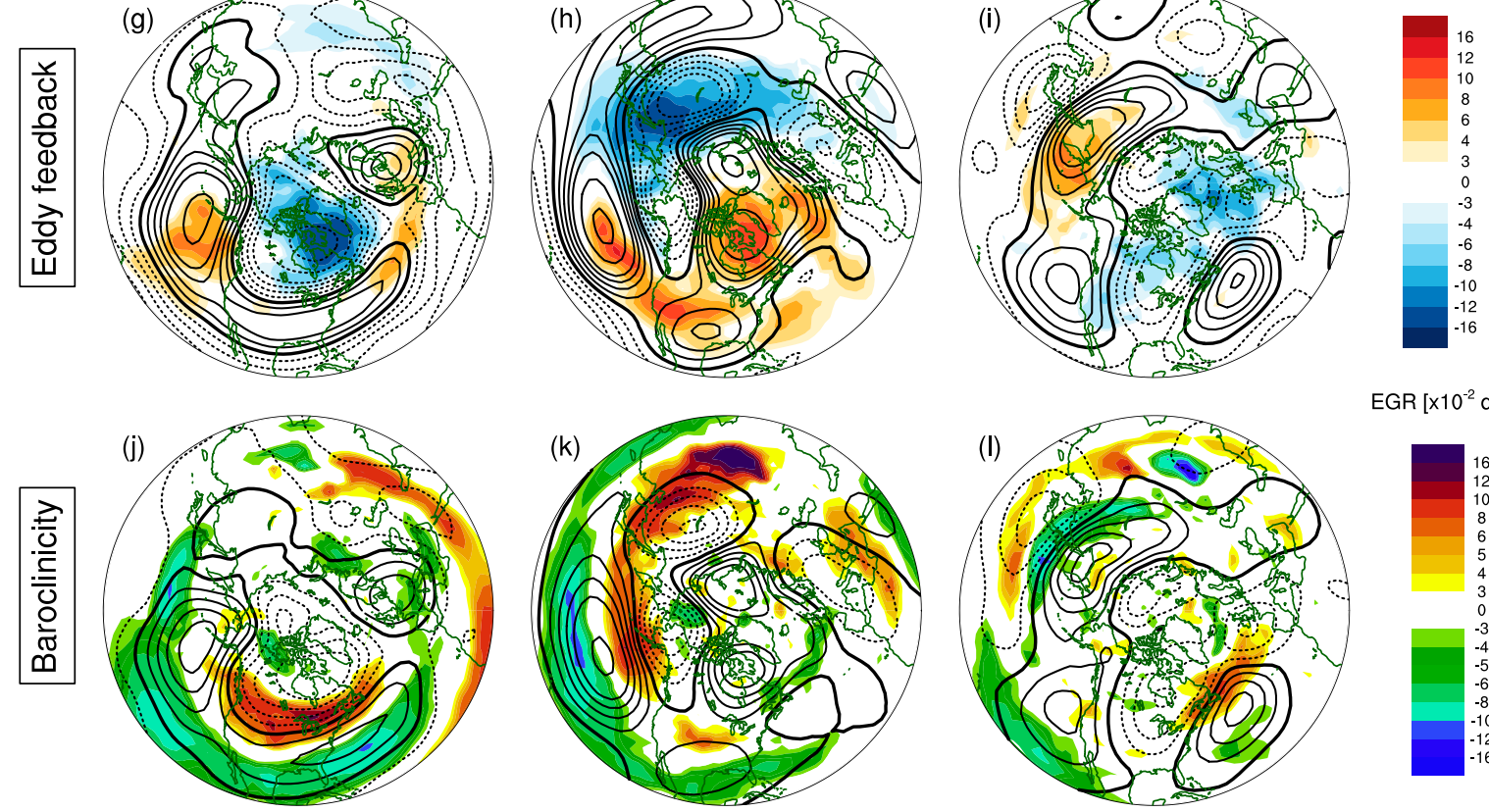

$\operatorname{EGR}\left[\times 10^{-2}\right.$ day $\left.^{-1}\right]$

FIG. 11. As in Figs. 8 and 9, but for JFM means and different stratospheric polar vortex strengths. (a),(d),(g),(i) Strong vortex, (b),(e),(h),(k) weak vortex, and (c),(f),(i),(l) neutral stratosphere. The weaker ENSO events (using the 0.5 standard deviation threshold) are considered here to separate between the different mean vortex strengths. Table 1 indicates the exact number of samples considered in each composite.

Baroclinicity and transient eddy feedback are shown in Fig. 11, where geopotential height anomalies are represented with contours for all six combinations of ENSO (EN, LN) and the polar vortex (strong, weak, neutral). The geopotential height tendency forced by transient eddies and the Eady growth rate is shown by the color shading. During EN the most relevant mechanism is the intense feedback of transient eddies, which maintain the clear negative NAO pattern in the weak vortex events (Fig. 11b). The baroclinicity feedback also 
(a) El Niño

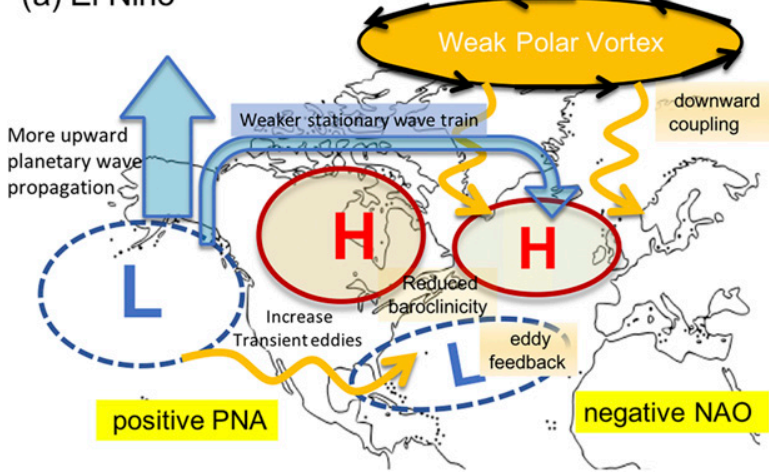

(b) La Niña

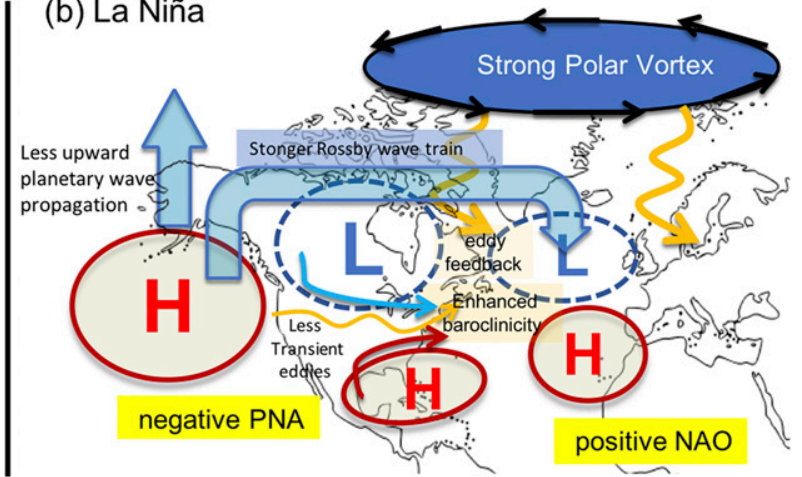

FIG. 12. Main mechanisms regarding the tropospheric pathway and the interaction with the stratosphere during (a) EN and (b) LN winters.

plays a major role in amplifying the downward signal, with a clear anomaly dipole matching the negative NAO geopotential anomaly pattern (Fig. 11e). Interestingly, during neutral vortex years, when the tropospheric pathway dominates, transient eddies force negative geopotential height anomalies from the Aleutian low to the west Atlantic (Fig. 11c), coinciding with the anomalous pathway of transient eddy propagation. Connected to this, baroclinicity is shifted southward in the same regions, as is the tropospheric jet. LN winters show a different picture, while the role of the tropospheric processes is similar. Under strong vortex events (Fig. 11g), the strongest anomalous eddy feedbacks are located in the northern lobe of the NAO, and weaker positive anomalies are located over the southern lobe. In this case the baroclinicity shift occurs from the Pacific all the way to the mid-Atlantic. We observe the strongest AL-IL seesaw signature (i.e., positive geopotential anomalies in the northern Pacific and negative anomalies near Iceland) during strong vortex conditions. This is related to the increased QS wave eastward propagation and the transient eddy feedback in the storm track region. Weak vortex events during LN (Fig. 11h) show a weak anomaly circulation pattern in the Atlantic, which is likely caused by the opposing effects of the tropospheric and stratospheric pathways. Finally, for a neutral vortex during LN (only 6 years) we find a substantial increase in baroclinicity in the Newfoundland region. This is consistent with the mechanism of Pinto et al. (2011) for negative PNA patterns. Negative eddy geopotential height forcing is also observed in the northern North Atlantic, where the negative geopotential anomalies are located.

\section{Summary and discussion}

In this study, the ENSO influence on the North Atlantic via tropospheric processes has been analyzed using ERA data. The teleconnection pattern in the North Atlantic differs between early winter (November-December) and mid-to-late winter (January-March). Here we have analyzed the mid-to-late winter response, which also differs for the warm and the cold phases of ENSO (i.e., EN and $\mathrm{LN})$. A negative NAO pattern is detected during EN from January to March, and a positive NAO is found during LN, in this case only for February. Figure 12 shows a schematic summary of the processes considered here, both for EN and LN conditions for the peak of the response. Because of the nature of this nonstationary signal monthly anomalies have been used instead of seasonal anomalies, which cannot account for the full picture of this response.

We have investigated the tropospheric mechanisms of the ENSO-North Atlantic relationship by examining the role of transient and quasi-stationary eddies by applying a series of dynamical diagnostic tools. Different formulations of wave activity flux have been computed for transient and quasi-stationary waves; moreover, we also computed transient eddy forcing in terms of geopotential height tendency and the maximum Eady growth rate. We then focused on the anomalous propagation of different types of waves and how they are modulated by ENSO and the stratospheric influence in late winter, helping to explain how the ENSO signal propagates across the Northern Hemisphere. Our results can be summarized as follows:

1) Downstream propagation of transient eddies is increased (decreased) over the southern part of North America during El Niño (La Niña) conditions. Using composites of the anomalous eastward propagation of these eddies (Figs. 3a-c) we show that they establish a connection between a deeper Aleutian low, where the eastward WAF is enhanced at its southern flank, with a negative NAO, where they propagate along the southern lobe. This confirms earlier studies showing a connection between the AL and the NAO via the downstream propagation of transient eddies (e.g., Li and Lau 2012b). 
2) Long quasi-stationary eastward-propagating Rossby wave trains $(k=1-3)$ increase during La Niña winters, most significantly in February when the polar vortex is strongest. On the other hand, our results show a clear decrease of the eastward propagation during El Niño from January to March. The anomalies in the eastward WAF of these waves can also link the AL with the NAO (Figs. 3g-i), which is in agreement with other studies (e.g., Sun and Tan 2013). Our study shows that ENSO significantly affects the eastward propagation of small wavenumbers $(k=1-3)$ and that the effect on the full zonal wavenumber spectrum of QS waves is of secondary importance and nonsignificant.

3) The southward (northward) shift of baroclinicity and transient eddy feedback during El Niño (La Niña) winters are important dynamical mechanisms for the maintenance of geopotential height anomalies from the North Pacific to the North Atlantic regions. These mechanisms are initiated in the North Pacific Ocean basin from early to midwinter, helping to maintain the southward or northward shift of the subtropical tropospheric jet there. The same is observed when geopotential anomalies reach the Atlantic Ocean, in January for EN and February for LN.

4) The stratospheric polar vortex can fundamentally alter the tropospheric pathway of ENSO. Our results show that the strongest influence on European winter climate happens during weak vortex events during El Niño, confirming previous studies (e.g., Butler et al. 2014). In contrast, the strongest signal in the Atlantic during La Niña occurs when the vortex is anomalously strong and more strongly able to channel long quasi-stationary waves from the Pacific to the Atlantic, establishing a stronger Aleutian-Icelandic seesaw (see, e.g., Castanheira and Graf 2003).

It should be kept in mind that this study focuses on the monthly averaged characteristics of the transient eddy forcing associated with ENSO and the polar vortex. Our analysis suggests strengthened linkages between the Pacific and the Atlantic during warm ENSO events. In general the North Atlantic circulation is driven on time scales of 10 days (Feldstein 2000). However, these time scales would be difficult to attribute to the ENSO signal. Our results, which are based on monthly averaged fields, include averages over several transient wave flux events, thus allowing us to identify the seasonal evolution of the teleconnection.
Note that the influence of the quasi-biennial oscillation (QBO), the Madden-Julian oscillation (MJO), or tropical Atlantic SST might further affect the described teleconnection (e.g., Hansen et al. 2016; Sung et al. 2013; Garfinkel and Hartmann 2010; Calvo et al. 2009; Toniazzo and Scaife 2006). These modes of variability can modulate the ENSO response in the extratropics by adding further nonlinearity to the system. Also, the sensitivity to the location of the tropical Pacific SST forcing (i.e., the ENSO flavor) has not been taken into account owing to the small number of available cases in reanalysis. Iza and Calvo (2015) and Calvo et al. (2017), using reanalysis and CMIP5 models, respectively, have found that central Pacific (CP) and east Pacific (EP) El Niños may lead to a different surface response in the North Atlantic and European sector. This is because the stratospheric pathway (occurrence of SSWs in this case) is more important for EP events as compared to CP events, with the latter showing a weaker impact on European winter climate. In this work we have used the Niño-3.4 region, which is more sensitive to EP events.

Because of the nonlinear and nonstationary nature of the ENSO response in the North Atlantic (e.g., Greatbatch 2004) and the limited period of the reanalysis, composites of variables of both ENSO and the polar vortex are not as robust as one would like. Because of this limitation, factors like the QBO and the flavor of ENSO cannot be separated. In the light of the discussed limitations a next step will have to include investigating the identified dynamical processes in a modeling study. However, our results are robust in the sense that changing the ENSO threshold does not alter the conclusions.

Acknowledgments. A large part of this work was performed while at GEOMAR Helmholtz Center for Ocean Research in Kiel. We are grateful to Katja Matthes and Richard Greatbatch for useful discussions of the preliminary results. We also want to thank Sandro Lubis for helpful discussions on some of the dynamical diagnostics employed in this study. Support from the Swiss National Science Foundation to both authors through project PP00P2_170523 is gratefully acknowledged. ERA-40 and ERA-Interim data were obtained from the ECMWF data server.

\section{APPENDIX A}

\section{Stationary 3D Wave Activity Flux}

The 3D wave activity flux (PB85) to diagnose the potential regional sources (sinks) and propagation 
characteristics of stationary planetary-scale wave activity and is computed as follows:

$$
\mathbf{F}_{s}=p \cos \phi\left\{\begin{array}{l}
\frac{1}{2 a^{2} \cos ^{2} \phi}\left[\left(\frac{\partial \psi^{*}}{\partial \lambda}\right)^{2}-\psi^{*} \frac{\partial^{2} \psi^{*}}{\partial \lambda^{2}}\right] \\
\frac{1}{2 a^{2} \cos \phi}\left(\frac{\partial \psi^{*}}{\partial \lambda} \frac{\partial \psi^{*}}{\partial \phi}-\psi^{*} \frac{\partial^{2} \psi^{*}}{\partial \lambda \partial \phi}\right) \\
\frac{2 \Omega^{2} \sin ^{2} \phi}{N^{2} a \cos \phi}\left(\frac{\partial \psi^{*}}{\partial \lambda} \frac{\partial \psi^{*}}{\partial z}-\psi^{*} \frac{\partial^{2} \psi^{*}}{\partial \lambda \partial z}\right)
\end{array}\right\},
$$

where $N$ is the buoyancy frequency, $\lambda$ is the longitude, $\varphi$ is the latitude, $a$ is Earth's radius, $p$ is the pressure normalized by $1000 \mathrm{hPa}$, and $\psi$ is the geostrophic streamfuction, which can be calculated as $\psi=\Psi / 2 \Omega \sin \varphi$, where $\Phi$ is the geopotential and $\Omega$ is Earth's angular velocity. Asterisks indicate departures from the zonal mean.

\section{APPENDIX B}

\section{Transient 3D Wave Activity Flux}

Plumb also developed a quasigeostrophic wave activity flux for transient waves $(c \neq 0)$ (PB86). Atmospheric variables are decomposed into the transient part, denoted by a prime, and its time mean part, denoted by an overbar. Starting from the linearized potential vorticity equation and assuming that the background flow is slowly varying, the transient WAF is defined as follows:

$$
\mathbf{M}_{T}=\mathbf{M}_{R}+\overline{\mathbf{u}} M,
$$

where $M=(1 / 2) p \cos \phi q^{\prime}\left|\nabla_{h} \bar{q}\right|$ is the quasigeostrophic transient wave activity or pseudomomentum, with $q$ being the quasigeostrophic potential vorticity and $p$ the pressure, $\mathbf{M}_{R}$ is the so-called radiative part of the flux, and $\overline{\mathbf{u}}$ is the low frequency horizontal wind. In the almostplane wave limit it holds that $\mathbf{M}_{T}=\mathbf{c}_{g} M$. Since $M$ is positive definite, $\mathbf{M}_{T}$ is everywhere parallel to the group velocity $\mathbf{c}_{g}$ of the eddies in the limit of WKB conditions. For quasigeostrophic flows, $\mathbf{M}_{R}=M_{R x} \mathbf{i}+M_{R y} \mathbf{j}+M_{R z} \mathbf{k}$ can be computed by the following:

$$
\begin{aligned}
& M_{R x}=\frac{p \cos \phi}{a_{e}\left|\nabla_{h} \bar{q}\right|}\left[\frac{\partial \bar{q}}{\cos \phi \partial \lambda} \overline{u^{\prime} v^{\prime}}+\frac{\partial \bar{q}}{\partial \phi}\left(\overline{v^{\prime 2}}-\varepsilon\right)\right], \\
& M_{R y}=\frac{p \cos \phi}{a_{e}\left|\nabla_{h} \bar{q}\right|}\left[\frac{\partial \bar{q}}{\cos \phi \partial \lambda}\left(\varepsilon-\overline{u^{\prime 2}}\right)-\frac{\partial \bar{q}}{\partial \phi} \overline{u^{\prime} v^{\prime}}\right], \text { and } \\
& M_{R z}=\frac{p \cos \phi}{a_{e}\left|\nabla_{h} \bar{q}\right|\left(d \theta_{0} / d z\right)}\left(\frac{\partial \bar{q}}{\cos \phi \partial \lambda} \overline{u^{\prime} \theta^{* \prime}}+\frac{\partial \bar{q}}{\partial \phi} \overline{v^{\prime} \theta^{* \prime}}\right),
\end{aligned}
$$

$$
\varepsilon=\frac{1}{2}\left(\overline{u^{\prime 2}}+\overline{v^{\prime 2}}+\frac{R p^{\kappa}}{H} \frac{\overline{\theta^{* 2}}}{d \theta_{0} / d z}\right)
$$

is the wave energy density, where $R$ is the gas constant of air, $\kappa=R / c_{p}=0.286$, and $H=7 \mathrm{~km}$ is the height scale. The parameter $\theta_{0}$ is the potential temperature averaged at each pressure level between $20^{\circ} \mathrm{N}$ and the pole. More details and discussion about the properties of this WAF can be found in PB86 or Nakamura et al. (2010).

\section{APPENDIX C}

\section{Transient Eddy Forcing of the Time-Mean Flow}

Transient eddies influence the atmospheric state by redistributing heat and vorticity in systematic fashion (Lau and Holopainen 1984). The net feedback forcing from synoptic scale transient eddies migrating along the tropospheric storm track can be described by the linearized QG potential vorticity equation written in the form of geopotential tendency:

$$
\begin{gathered}
{\left[\nabla^{2}+f^{2} \frac{\partial}{\partial p}\left(\frac{1}{S} \frac{\partial}{\partial p}\right)\right] \frac{\partial \bar{Z}}{\partial t}=-\frac{f}{g} \nabla \cdot\left(\overline{\mathbf{u}^{\prime} \zeta^{\prime}}\right)} \\
+\frac{f^{2}}{g} \frac{\partial}{\partial p}\left[\frac{\nabla \cdot\left(\overline{\mathbf{u}^{\prime} \theta^{\prime}}\right)}{-(\partial \Theta / \partial p)}\right],
\end{gathered}
$$

where the term on the left-hand side is the 3D Laplacian operator in pressure coordinates applied to the mean geopotential tendency. On the right-hand side, the first term represents the contribution from the vorticity advection by the transient eddies, and the second term represents the contribution from the heat advection. Lau and Holopainen (1984) demonstrated that in the upper troposphere the vorticity advection clearly dominates the geopotential forcing by the transient eddies. So we can derive an approximate expression for the geopotential tendency at $250 \mathrm{hPa}$ :

$$
\left(\frac{\partial Z_{250}}{\partial t}\right)_{\mathrm{TE}}=\frac{f_{g}}{g} \nabla^{-2}\left[-\nabla \cdot\left(\overline{\left(\mathbf{u}^{\prime} \zeta^{\prime}\right.}\right)\right],
$$

where $f$ is the Coriolis parameter, $g$ is the gravity constant, and $\eta$ is the relative vorticity. Primes indicate high frequency and overbars low frequency. In our analysis, we used bandpass frequencies between 2 and 8 days (primes) and low-pass frequencies of more than 30 days (overbars). 


\section{REFERENCES}

Baldwin, M. P., and T. J. Dunkerton, 2001: Stratospheric harbingers of anomalous weather regimes. Science, 294, 581-584, https://doi.org/10.1126/science.1063315.

— , and D. W. Thompson, 2009: A critical comparison of stratosphere-troposphere coupling indices. Quart. J. Roy. Meteor. Soc., 135, 1661-1672, https://doi.org/10.1002/qj.479.

Barnston, A. G., and R. E. Livezey, 1987: Classification, seasonality and persistence of low-frequency atmospheric circulation patterns. Mon. Wea. Rev., 115, 1083-1126, https://doi.org/ 10.1175/1520-0493(1987)115<1083:CSAPOL $>2.0$.CO;2.

Barriopedro, D., and N. Calvo, 2014: On the relationship between ENSO, stratospheric sudden warmings, and blocking. J. Climate, 27, 4704-4720, https://doi.org/10.1175/ JCLI-D-13-00770.1.

Basnett, T. A., and D. E. Parker, 1997: Development of the global mean sea level pressure data set GMSLP. Climate Research Tech. Note 79, 16 pp.

Brönnimann, S., 2007: Impact of El Niño-Southern Oscillation on European climate. Rev. Geophys., 45, RG3003, https://doi.org/ 10.1029/2006RG000199.

Butler, A. H., and L. M. Polvani, 2011: El Niño, La Niña, and stratospheric sudden warmings: A reevaluation in light of the observational record. Geophys. Res. Lett., 38, L13807, https:// doi.org/10.1029/2011GL048084.

, - - and C. Deser, 2014: Separating the stratospheric and tropospheric pathways of El Niño-Southern Oscillation teleconnections. Environ. Res. Lett., 9, 024014, https://doi.org/ 10.1088/1748-9326/9/2/024014.

— , and Coauthors, 2016: The Climate-System Historical Forecast Project: Do stratosphere-resolving models make better seasonal climate predictions in boreal winter? Quart. J. Roy. Meteor. Soc., 142, 1413-1427, https://doi.org/10.1002/qj.2743.

Cagnazzo, C., and E. Manzini, 2009: Impact of the stratosphere on the winter tropospheric teleconnections between ENSO and the North Atlantic and European region. J. Climate, 22, 12231238, https://doi.org/10.1175/2008JCLI2549.1.

Calvo, N., M. A. Giorgetta, R. Garcia-Herrera, and E. Manzini, 2009: Nonlinearity of the combined warm ENSO and QBO effects on the Northern Hemisphere polar vortex in MAECHAM5 simulations. J. Geophys. Res., 114, D13109, https:// doi.org/10.1029/2008JD011445.

_ _ and Coauthors, 2017: Northern Hemisphere stratospheric pathway of different El Niño flavors in stratosphere-resolving CMIP5 models. J. Climate, 30, 4351-4371, https://doi.org/ 10.1175/JCLI-D-16-0132.1.

Castanheira, J. M., and H. Graf, 2003: North Pacific-North Atlantic relationships under stratospheric control? J. Geophys. Res., 108, 4036, https://doi.org/10.1029/2002JD002754.

Charney, J. G., and P. G. Drazin, 1961: Propagation of planetaryscale disturbances from the lower into the upper atmosphere. J. Geophys. Res., 66, 83-109, https://doi.org/10.1029/ JZ066i001p00083.

Dee, D. P., and Coauthors, 2011: The ERA-Interim reanalysis: Configuration and performance of the data assimilation system. Quart. J. Roy. Meteor. Soc., 137, 553-597, https://doi.org/ 10.1002/qj.828.

Deser, C., I. R. Simpson, K. A. McKinnon, and A. S. Phillips, 2017: The Northern Hemisphere extratropical atmospheric circulation response to ENSO: How well do we know it and how do we evaluate models accordingly? J. Climate, 30, 5059-5082, https://doi.org/10.1175/JCLI-D-16-0844.1.
Domeisen, D. I. V., A. H. Butler, K. Fröhlich, M. Bittner, W. A. Müller, and J. Baehr, 2015: Seasonal predictability over Europe arising from El Niño and stratospheric variability in the MPI-ESM seasonal prediction system. J. Climate, 28, 256271, https://doi.org/10.1175/JCLI-D-14-00207.1.

Drouard, M., G. Rivière, and P. Arbogast, 2013: The North Atlantic Oscillation response to large-scale atmospheric anomalies in the northeastern Pacific. J. Atmos. Sci., 70, 2854-2874, https://doi.org/10.1175/JAS-D-12-0351.1.

,-- , and -2015 : The link between the North Pacific climate variability and the North Atlantic Oscillation via downstream propagation of synoptic waves. J. Climate, $\mathbf{2 8}$, 3957-3976, https://doi.org/10.1175/JCLI-D-14-00552.1.

Edmon, H. J., B. J. Hoskins, and M. E. McIntyre, 1980: EliassenPalm cross sections for the troposphere. J. Atmos. Sci., 37, 2600-2616, https://doi.org/10.1175/1520-0469(1980)037<2600: EPCSFT $>2.0 . \mathrm{CO} ; 2$.

Egger, J., 1978: Dynamics of blocking highs. J. Atmos. Sci., 35, 1788-1801, https://doi.org/10.1175/1520-0469(1978)035<1788: $\mathrm{DOBH}>2.0 . \mathrm{CO} ; 2$.

Feldstein, S. B., 2000: The timescale, power spectra, and climate noise properties of teleconnection patterns. J. Climate, $\mathbf{1 3}$ 4430-4440, https://doi.org/10.1175/1520-0442(2000)013<4430: TTPSAC $>2.0 . \mathrm{CO} ; 2$.

Feng, J., W. Chen, and Y. Li, 2017: Asymmetry of the winter extratropical teleconnections in the Northern Hemisphere associated with two types of ENSO. Climate Dyn., 48, 2135-2151, https://doi.org/10.1007/s00382-016-3196-2.

Frauen, C., D. Dommenget, N. Tyrrell, M. Rezny, and S. Wales, 2014: Analysis of the nonlinearity of El Niño-Southern Oscillation teleconnections. J. Climate, 27, 6225-6244, https:// doi.org/10.1175/JCLI-D-13-00757.1.

Garfinkel, C. I., and D. L. Hartmann, 2010: Influence of the quasibiennial oscillation on the North Pacific and El Niño teleconnections. J. Geophys. Res., 115, D20116, https://doi.org/ 10.1029/2010JD014181.

- - - , and F. Sassi, 2010: Tropospheric precursors of anomalous Northern Hemisphere stratospheric polar vortices. J. Climate, 23, 3282-3299, https://doi.org/10.1175/ 2010JCLI3010.1.

- A. H. Butler, D. W. Waugh, M. M. Hurwitz, and L. M. Polvani, 2012: Why might stratospheric sudden warmings occur with similar frequency in El Niño and La Niña winters? J. Geophys. Res., 117, D19106, https://doi.org/ 10.1029/2012JD017777.

— M. M. Hurwitz, D. W. Waugh, and A. H. Butler, 2013: Are the teleconnections of central Pacific and eastern Pacific El Niño distinct in boreal wintertime? Climate Dyn., 41, 18351852, https://doi.org/10.1007/s00382-012-1570-2.

Greatbatch, R. J., 2004: Nonstationary impact of ENSO on EuroAtlantic winter climate. Geophys. Res. Lett., 31, L02208, https://doi.org/10.1029/2003GL018542.

Hansen, F., K. Matthes, and S. Wahl, 2016: Tropospheric QBOENSO interactions and differences between the Atlantic and Pacific. J. Climate, 29, 1353-1368, https://doi.org/10.1175/ JCLI-D-15-0164.1.

Honda, M., and H. Nakamura, 2001: Interannual seesaw between the Aleutian and Icelandic lows. Part II: Its significance in the interannual variability over the wintertime Northern Hemisphere. J. Climate, 14, 4512-4529, https://doi.org/10.1175/ 1520-0442(2001)014<4512:ISBTAA > 2.0.CO; 2 .

-,- J. Ukita, I. Kousaka, and K. Takeuchi, 2001: Interannual seesaw between the Aleutian and Icelandic lows. 
Part I: Seasonal dependence and life cycle. J. Climate, 14, 1029-1042, https://doi.org/10.1175/1520-0442(2001)014<1029: ISBTAA $>2.0 . \mathrm{CO} ; 2$.

_- Y. Kushnir, H. Nakamura, S. Yamane, and S. E. Zebiak, 2005a: Formation, mechanisms, and predictability of the Aleutian-Icelandic low seesaw in ensemble AGCM simulations. J. Climate, 18, 1423-1434, https://doi.org/10.1175/ JCLI3353.1.

- S. Yamane, and H. Nakamura, 2005b: Impacts of the Aleutian-Icelandic low seesaw on surface climate during the twentieth century. J. Climate, 18, 2793-2802, https://doi.org/ 10.1175/JCLI3419.1.

Horel, J. D., and J. M. Wallace, 1981: Planetary-scale atmospheric phenomena associated with the Southern Oscillation. Mon. Wea. Rev., 109, 813-829, https://doi.org/10.1175/ 1520-0493(1981)109<0813:PSAPAW>2.0.CO;2.

Hoskins, B. J., and D. J. Karoly, 1981: The steady linear response of a spherical atmosphere to thermal and orographic forcing. J. Atmos. Sci., 38, 1179-1196, https://doi.org/10.1175/ 1520-0469(1981)038<1179:TSLROA > 2.0.CO;2.

—, I. N. James, and G. H. White, 1983: The shape, propagation and mean-flow interaction of large-scale weather systems. J. Atmos. Sci., 40, 1595-1612, https://doi.org/10.1175/ 1520-0469(1983)040<1595:TSPAMF $>2.0 . \mathrm{CO} ; 2$.

Huang, B., and Coauthors, 2015: Extended Reconstructed Sea Surface Temperature version 4 (ERSST.v4). Part I: Upgrades and intercomparisons. J. Climate, 28, 911-930, https://doi.org/ 10.1175/JCLI-D-14-00006.1.

Ineson, S., and A. A. Scaife, 2009: The role of the stratosphere in the European climate response to El Niño. Nat. Geosci., 2, 32 36, https://doi.org/10.1038/ngeo381.

Iza, M., and N. Calvo, 2015: Role of stratospheric sudden warmings on the response to central Pacific El Niño. Geophys. Res. Lett., 42, 2482-2489, https://doi.org/10.1002/ 2014GL062935.

— - _ - and E. Manzini, 2016: The stratospheric pathway of La Niña. J. Climate, 29, 8899-8914, https://doi.org/10.1175/ JCLI-D-16-0230.1.

Kidston, J., A. A. Scaife, S. C. Hardiman, D. M. Mitchell, N. Butchart, M. P. Baldwin, and L. J. Gray, 2015: Stratospheric influence on tropospheric jet streams, storm tracks and surface weather. Nat. Geosci., 8, 433-440, https://doi.org/ 10.1038/ngeo2424.

Kobayashi, S., and Coauthors, 2015: The JRA-55 reanalysis: General specifications and basic characteristics. $J$ Meteor. Soc. Japan, 93, 5-48, https://doi.org/10.2151/ jmsj.2015-001.

Lau, N.-C., and E. Holopainen, 1984: Transient eddy forcing of the time-mean flow as identified by geopotential tendencies. J. Atmos. Sci., 41, 313-328, https://doi.org/10.1175/ 1520-0469(1984)041<0313:TEFOTT >2.0.CO;2.

Li, Y., and N. C. Lau, 2012a: Contributions of downstream eddy development to the teleconnection between ENSO and the atmospheric circulation over the North Atlantic. J. Climate, 25, 4993-5010, https://doi.org/10.1175/ JCLI-D-11-00377.1.

— variability over the North Atlantic in late winter-Role of transient eddies. J. Climate, 25, 320-342, https://doi.org/ 10.1175/JCLI-D-11-00037.1.

Liu, Z., and M. Alexander, 2007: Atmospheric bridge, oceanic tunnel, and global climatic teleconnections. Rev. Geophys., 45, RG2005, https://doi.org/10.1029/2005RG000172.
López-Parages, J., B. Rodríguez-Fonseca, D. Dommenget, and C. Frauen, 2016: ENSO influence on the North Atlantic European climate: A non-linear and non-stationary approach. Climate Dyn., 47, 2071-2084, https://doi.org/ 10.1007/s00382-015-2951-0.

Lorenz, D., and D. Hartmann, 2001: Eddy-zonal flow feedback in the Southern Hemisphere winter and summer. J. Atmos. Sci., 58, 3312-3327, https://doi.org/10.1175/1520-0469(2001) $058<3312$ :EZFFIT $>2.0 . \mathrm{CO} ; 2$.

Manzini, E., 2009: Atmospheric science: ENSO and the stratosphere. Nat. Geosci., 2, 749-750, https://doi.org/10.1038/ ngeo677.

Moron, V., and I. Gouirand, 2003: Seasonal modulation of the El Niño-Southern Oscillation relationship with sea level pressure anomalies over the North Atlantic in October-March 1873-1996. Int. J. Climatol., 23, 143-155, https://doi.org/ 10.1002/joc.868.

Nakamura, H., and M. Honda, 2002: Interannual seesaw between the Aleutian and Icelandic lows. Part III: Its influence upon the stratospheric variability. J. Meteor. Soc. Japan, 80, 10511067, https://doi.org/10.2151/jmsj.80.1051.

Nakamura, M., M. Kadota, and S. Yamane, 2010: Quasigeostrophic transient wave activity flux: Updated climatology and its role in polar vortex anomalies. J. Atmos. Sci., 67, 3164-3189, https://doi.org/10.1175/2010JAS3451.1

- — , and — 2011: Corrigendum. J. Atmos. Sci., 68, 18411842, https://doi.org/10.1175/JAS-D-11-074.1.

Orsolini, J. Y., N. G. Kvamstø, I. T. Kindem, M. Honda, and H. Nakamura, 2008: Influence of the Aleutian-Icelandic low seesaw and ENSO onto the stratosphere in ensemble winter hindcasts. J. Meteor. Soc. Japan, 86, 817-825, https://doi.org/ $10.2151 /$ jmsj.86.817.

Pinto, J. G., M. Reyers, and U. Ulbrich, 2011: The variable link between PNA and NAO in observations and in multi-century CGCM simulations. Climate Dyn., 36, 337-354, https://doi.org/ 10.1007/s00382-010-0770-x.

Plumb, R. A., 1985: On the three-dimensional propagation of stationary waves. J. Atmos. Sci., 42, 217-229, https://doi.org/ 10.1175/1520-0469(1985)042<0217:OTTDPO>2.0.CO;2.

1986: Three-dimensional propagation of transient quasigeostrophic eddies and its relationship with the eddy forcing of the time-mean flow. J. Atmos. Sci., 43, 1657-1678, https:// doi.org/10.1175/1520-0469(1986)043<1657:TDPOTQ>2.0.CO;2.

, and K. Semeniuk, 2003: Downward migration of extratropical zonal wind anomalies. J. Geophys. Res., 108, 4223, https://doi.org/10.1029/2002JD002773.

Polvani, L. M., L. Sun, A. H. Butler, J. H. Richter, and C. Deser, 2017: Distinguishing stratospheric sudden warmings from ENSO as key drivers of wintertime climate variability over the North Atlantic and Eurasia. J. Climate, 30, 1959-1969, https:// doi.org/10.1175/JCLI-D-16-0277.1.

Richter, J. H., C. Deser, and L. Sun, 2015: Effects of stratospheric variability on El Niño teleconnections. Environ. Res. Lett., 10, 124021, https://doi.org/10.1088/1748-9326/10/ $12 / 124021$

Rodríguez-Fonseca, B., and Coauthors, 2016: A review of ENSO influence on the North Atlantic. A non-stationary signal. Atmosphere, 7, 87, https://doi.org/10.3390/atmos7070087.

Sun, J., and B. Tan, 2013: Mechanism of the wintertime Aleutian Low-Icelandic Low seesaw. Geophys. Res. Lett., 40, 41034108, https://doi.org/10.1002/grl.50770.

Sung, M. K., Y. G. Ham, J. S. Kug, and S. I. An, 2013: An alternative effect by the tropical North Atlantic SST in 
intraseasonally varying El Niño teleconnection over the North Atlantic. Tellus, 65A, 19863, https://doi.org/10.3402/ tellusa.v65i0.19863.

Takaya, K., and H. Nakamura, 1997: A formulation of a wave activity flux for stationary Rossby waves on a zonally varying basic flow. Geophys. Res. Lett., 24, 2985-2988, https://doi.org/ 10.1029/97GL03094.

, and —, 2001: A formulation of a phase-independent wave-activity flux for stationary and migratory quasigeostrophic eddies on a zonally varying basic flow. J. Atmos. Sci., 58, 608-627, https://doi.org/10.1175/1520-0469(2001)058<0608: AFOAPI $>2.0 . \mathrm{CO} ; 2$.
Toniazzo, T., and A. A. Scaife, 2006: The influence of ENSO on winter North Atlantic climate. Geophys. Res. Lett., 33, L24704, https://doi.org/10.1029/2006GL027881.

Uppala, S. M., and Coauthors, 2005: The ERA-40 Re-Analysis. Quart. J. Roy. Meteor. Soc., 131, 2961-3012, https://doi.org/ 10.1256/qj.04.176.

Vallis, G. K., 2013: Atmospheric and Oceanic Fluid Dynamics. Cambridge University Press, 769 pp.

Zhang, T., J. Perlwitz, and M. P. Hoerling, 2014: What is responsible for the strong observed asymmetry in teleconnections between El Niño and La Niña? Geophys. Res. Lett., 41, 1019-1025, https://doi.org/10.1002/2013GL058964. 